ol051407 Supporting Information, part 2

\title{
Intramolecular Reactions of Hydroperoxides
}

and Oxetanes: Stereoselective Synthesis of 1,2-

\section{Dioxolanes and 1,2-Dioxanes}

\author{
Peng Dai and Patrick H. Dussault* \\ Department of Chemistry, University of \\ Nebraska-Lincoln, Lincoln, NE 68588-0304 \\ pdussault1@unl.edu
}

NMR spectra (58 spectra, 59 pages inclusive) 
Page 2

Compound 1a<smiles>[AlH2]</smiles>

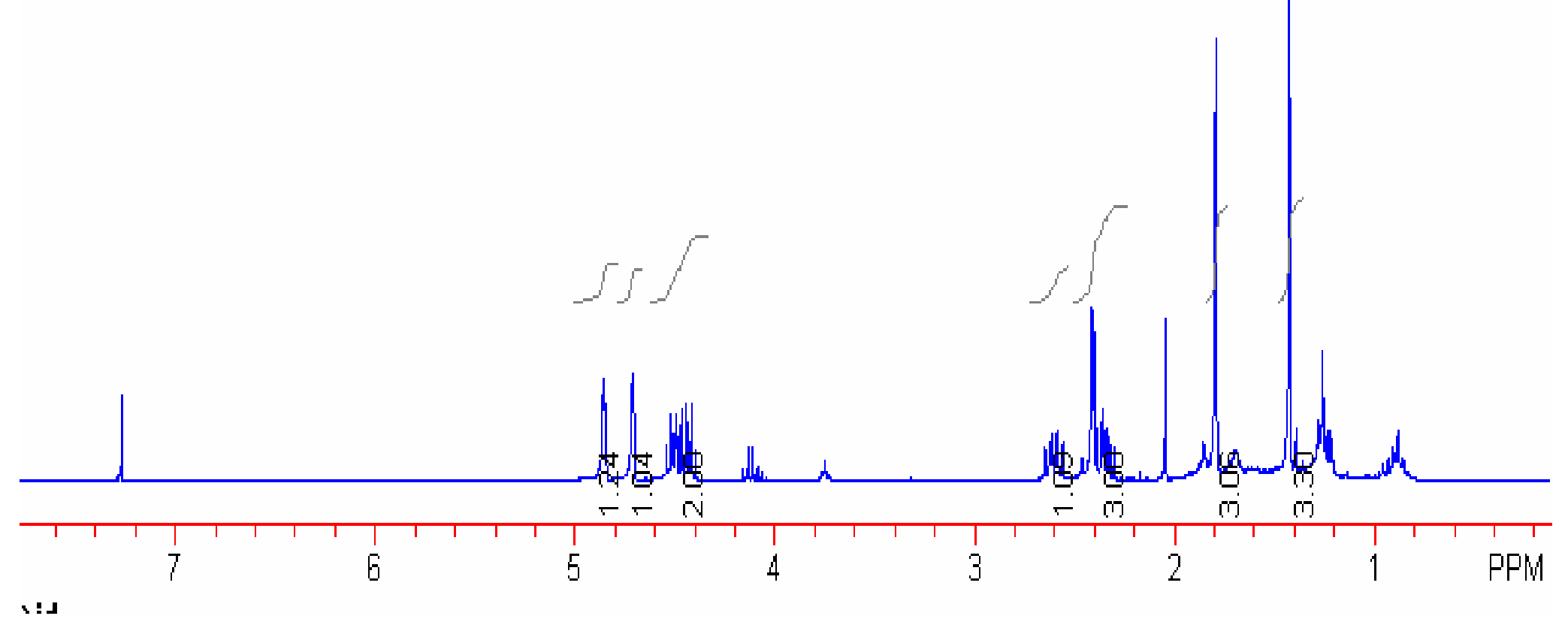



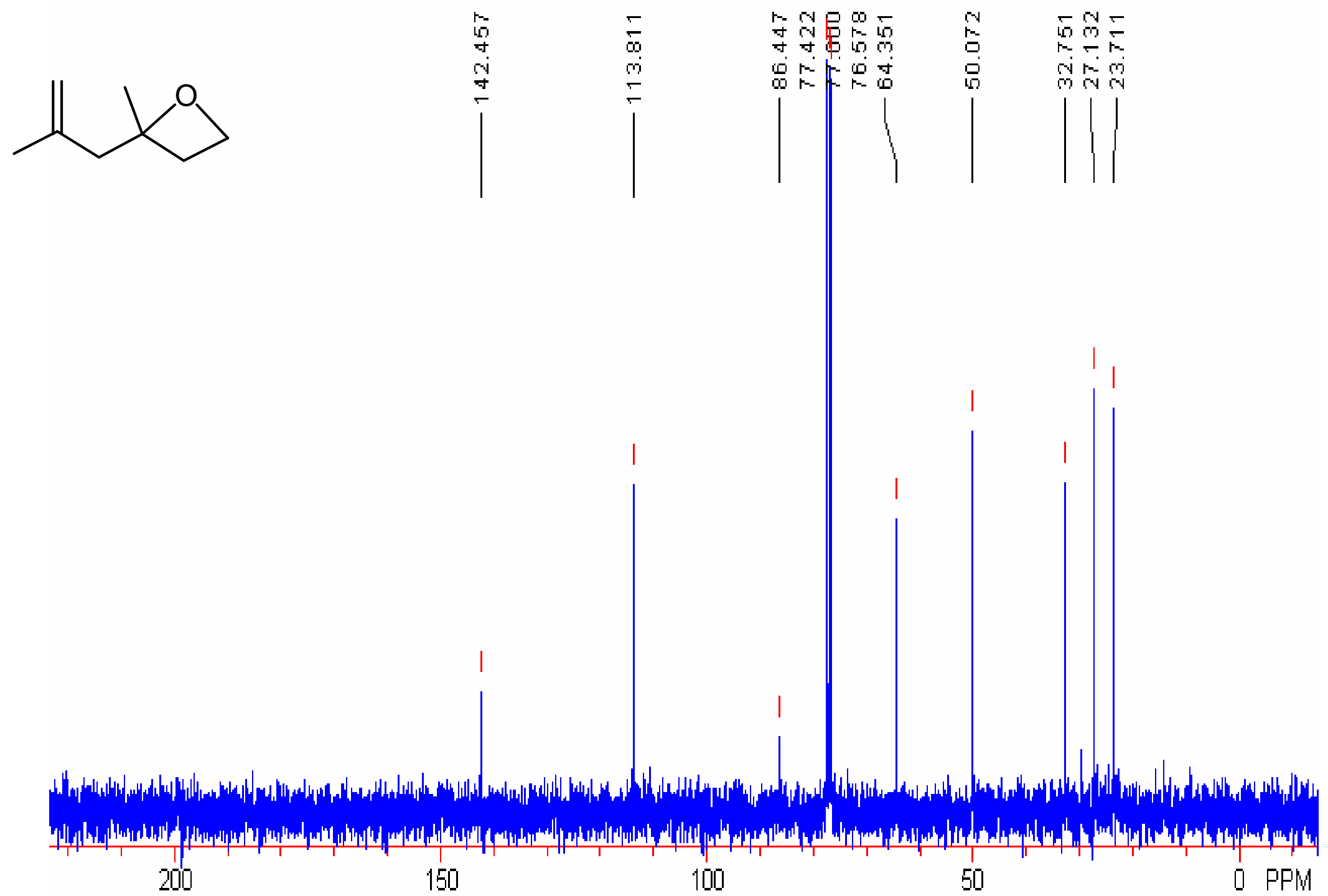
<smiles>COC1(C)CC(C)(CCO)OO1</smiles>

$V^{1}$

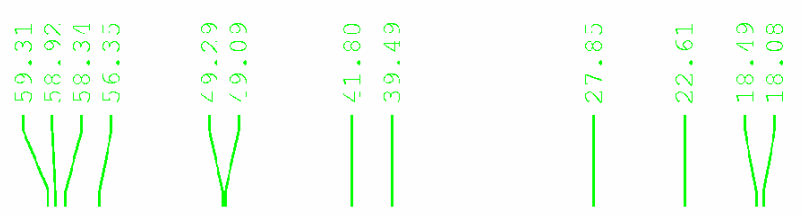

Page 5

Compound $1 \mathrm{c}$ 

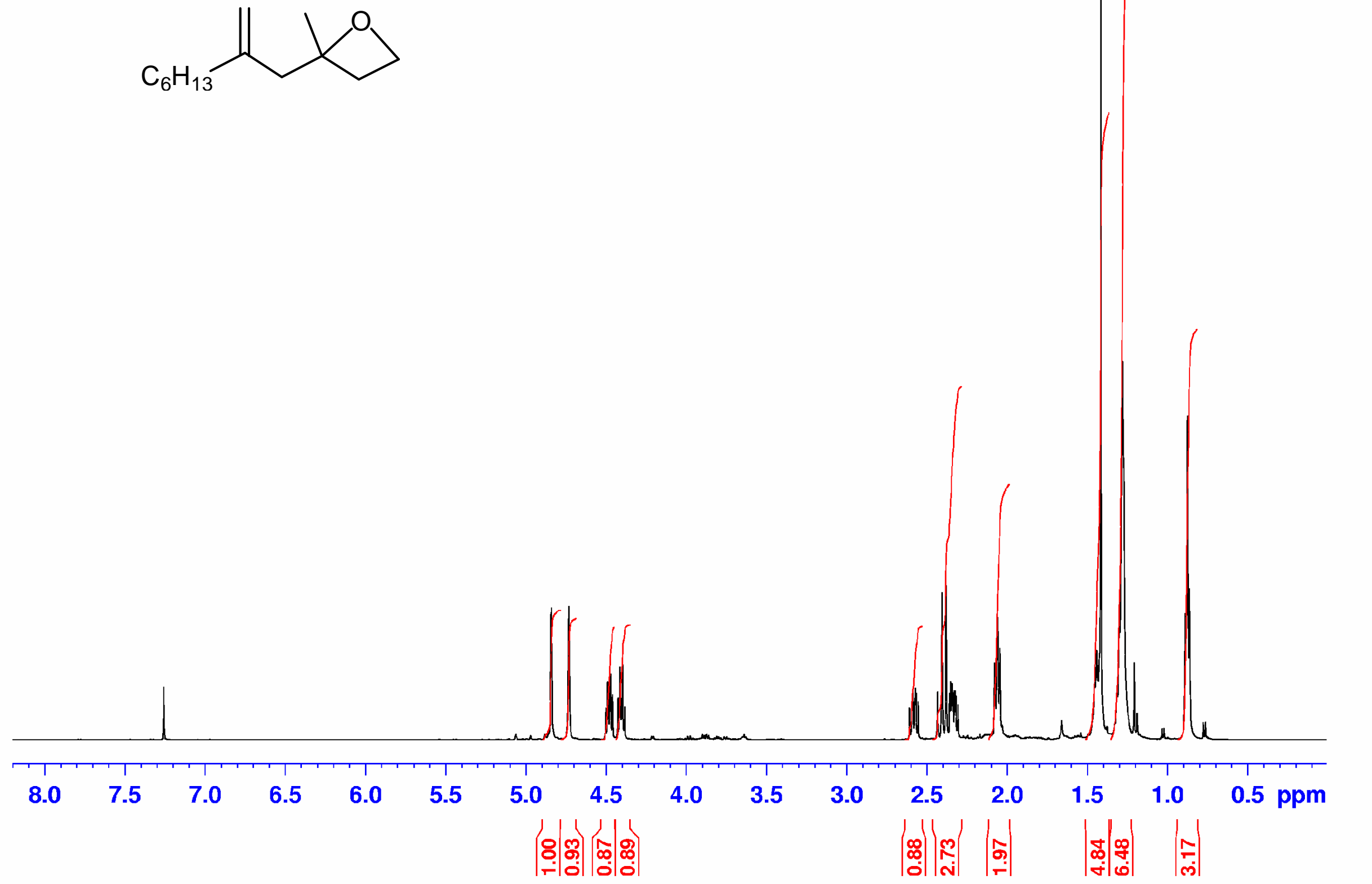


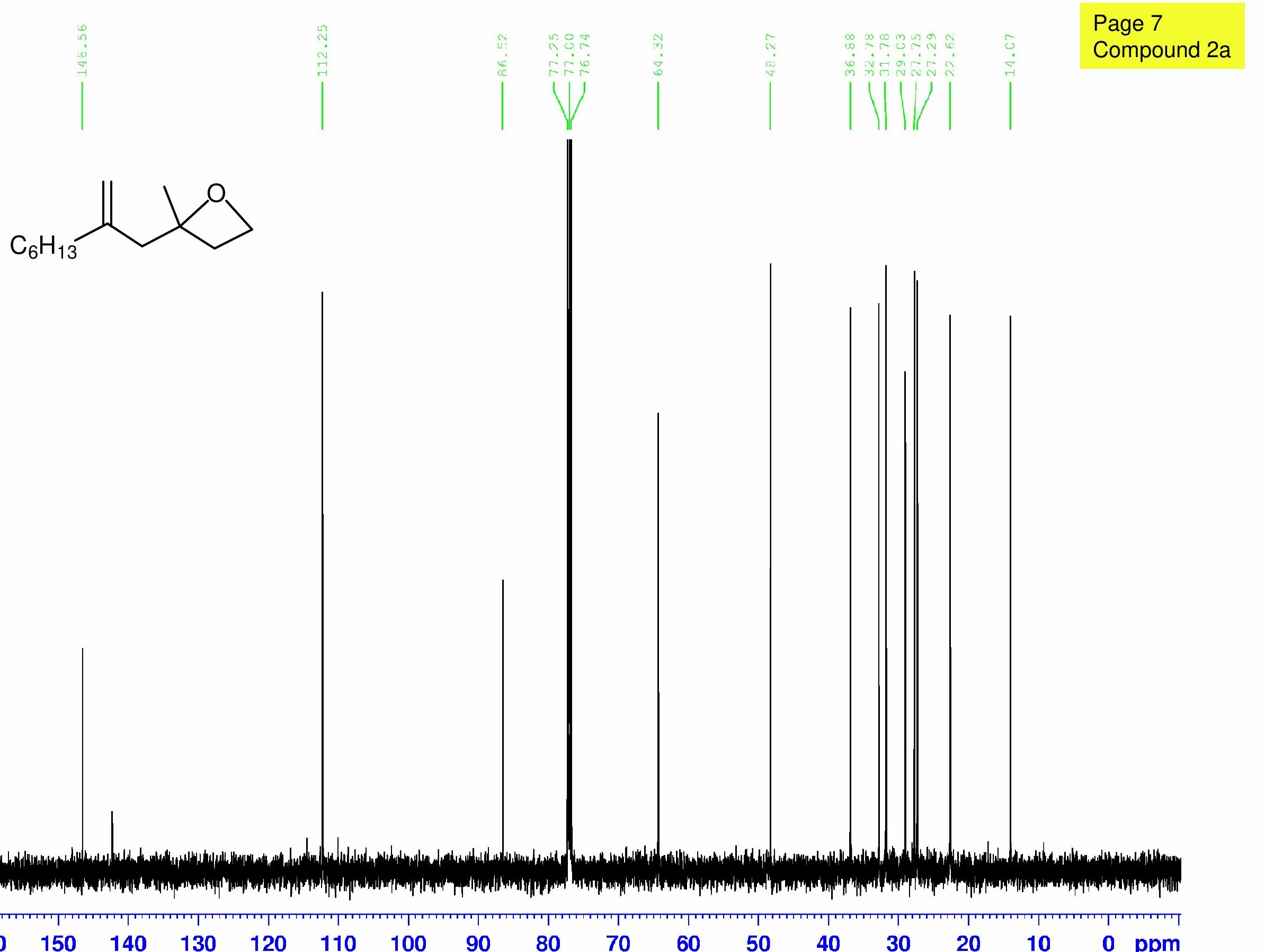


<smiles>COC1([15CH2])CC(C)(CCO)OO1</smiles>

Page 8

Compound 2c 

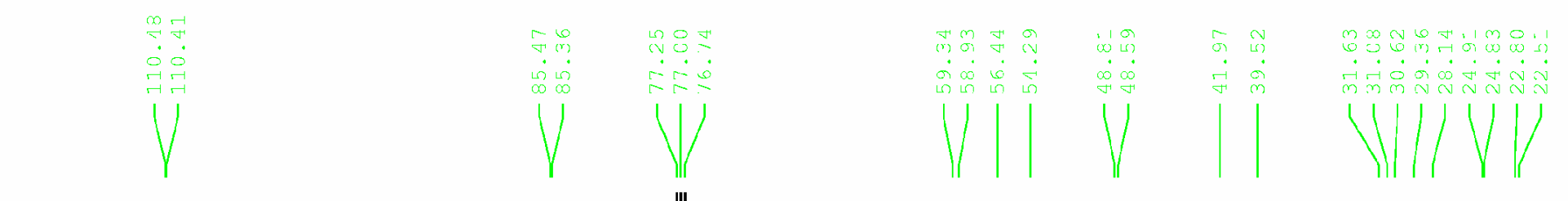

Page 9

Compound 2c<smiles>COC1([16CH2])CC(C)(CCO)OO1</smiles>

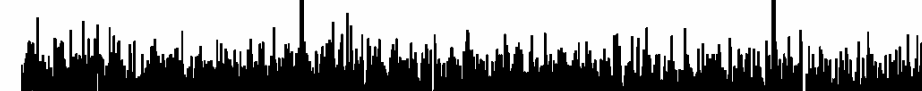

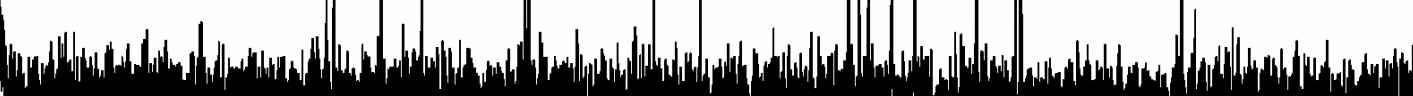

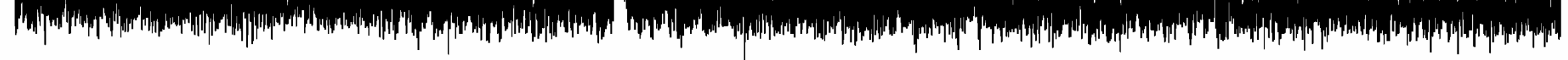

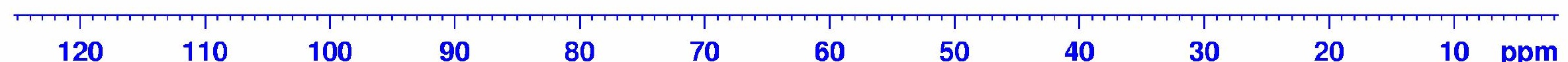



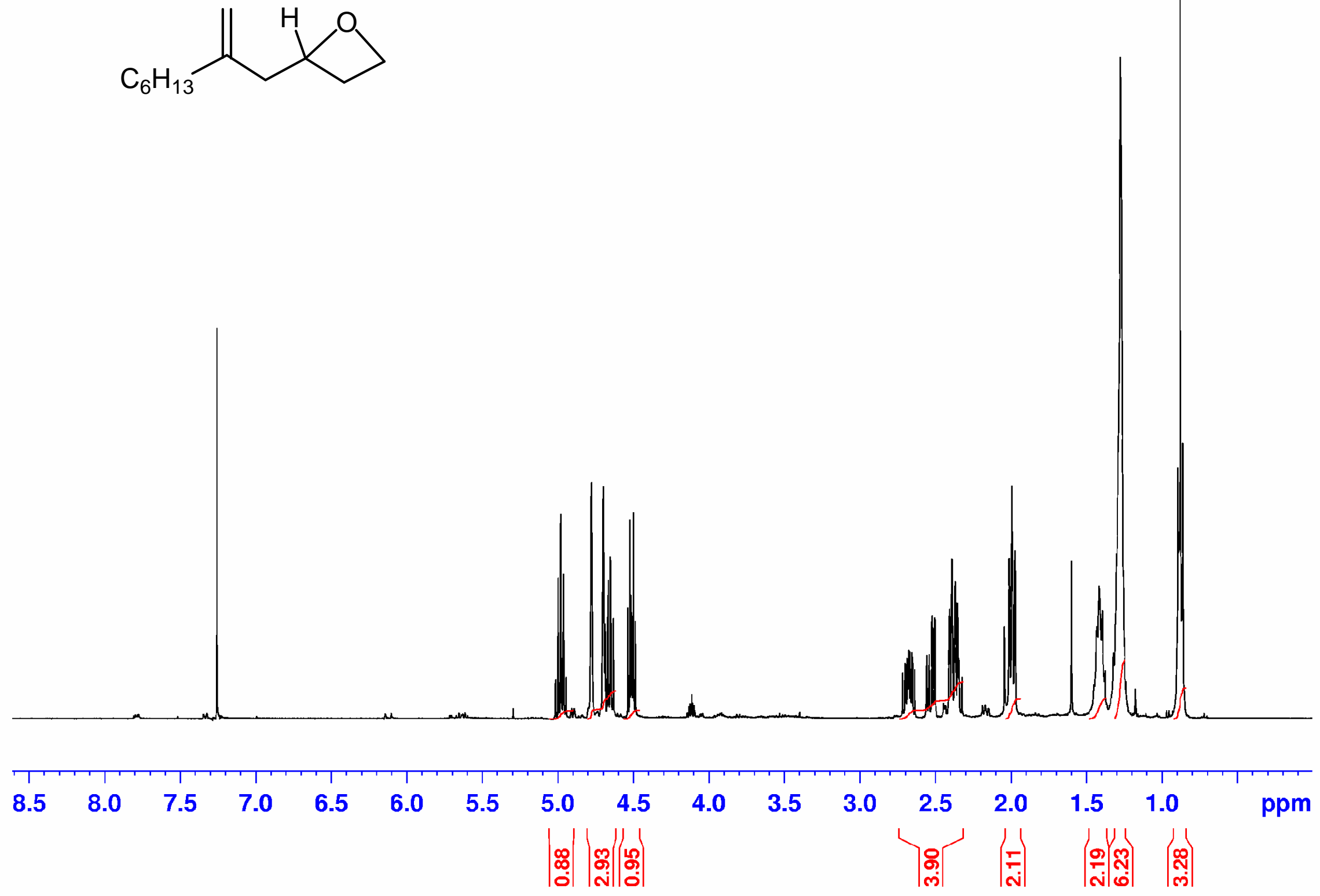


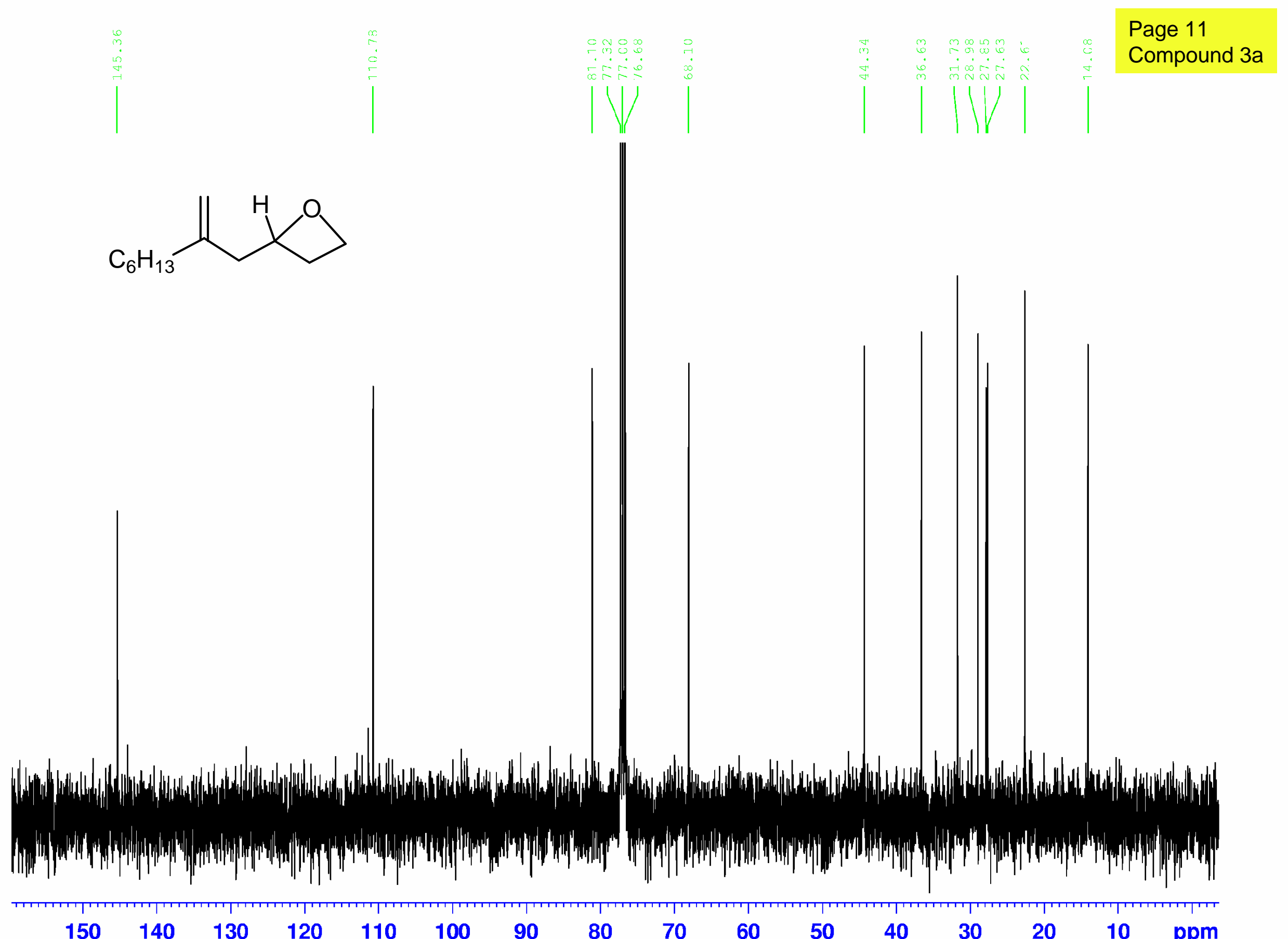




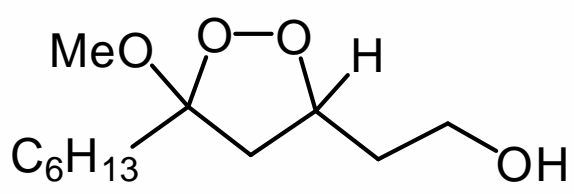



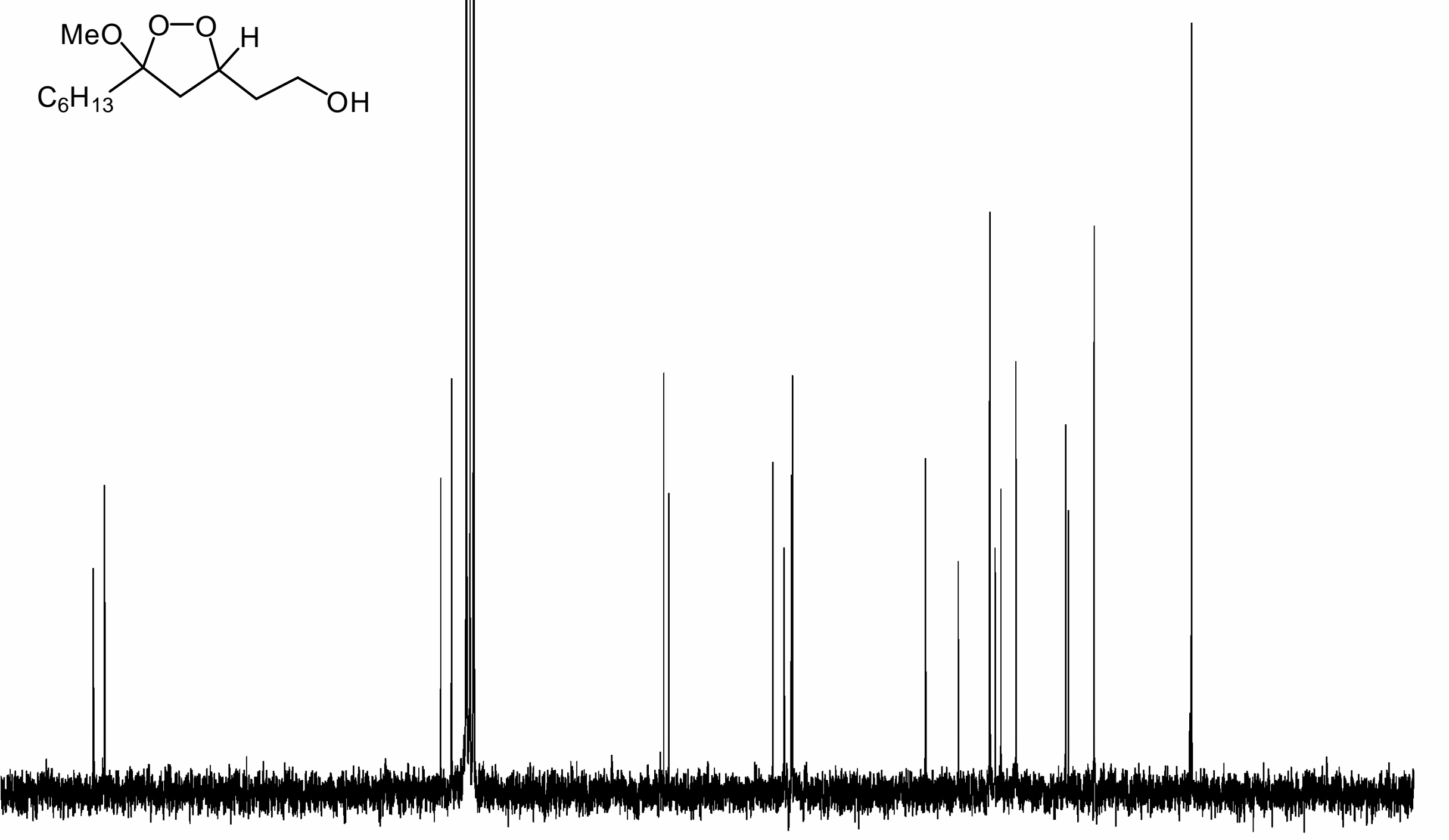
<smiles>C=C(CCCCCCCCCC)CC1(C)OC[C@@H]1C</smiles>

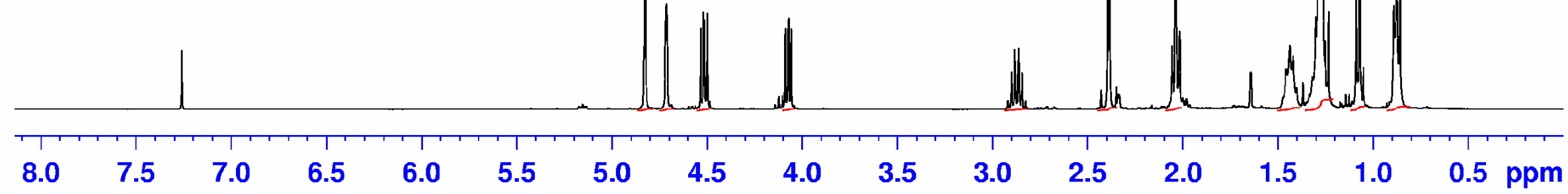

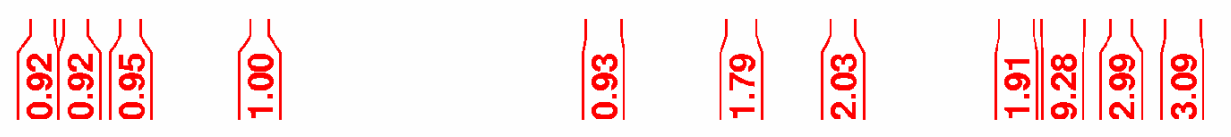




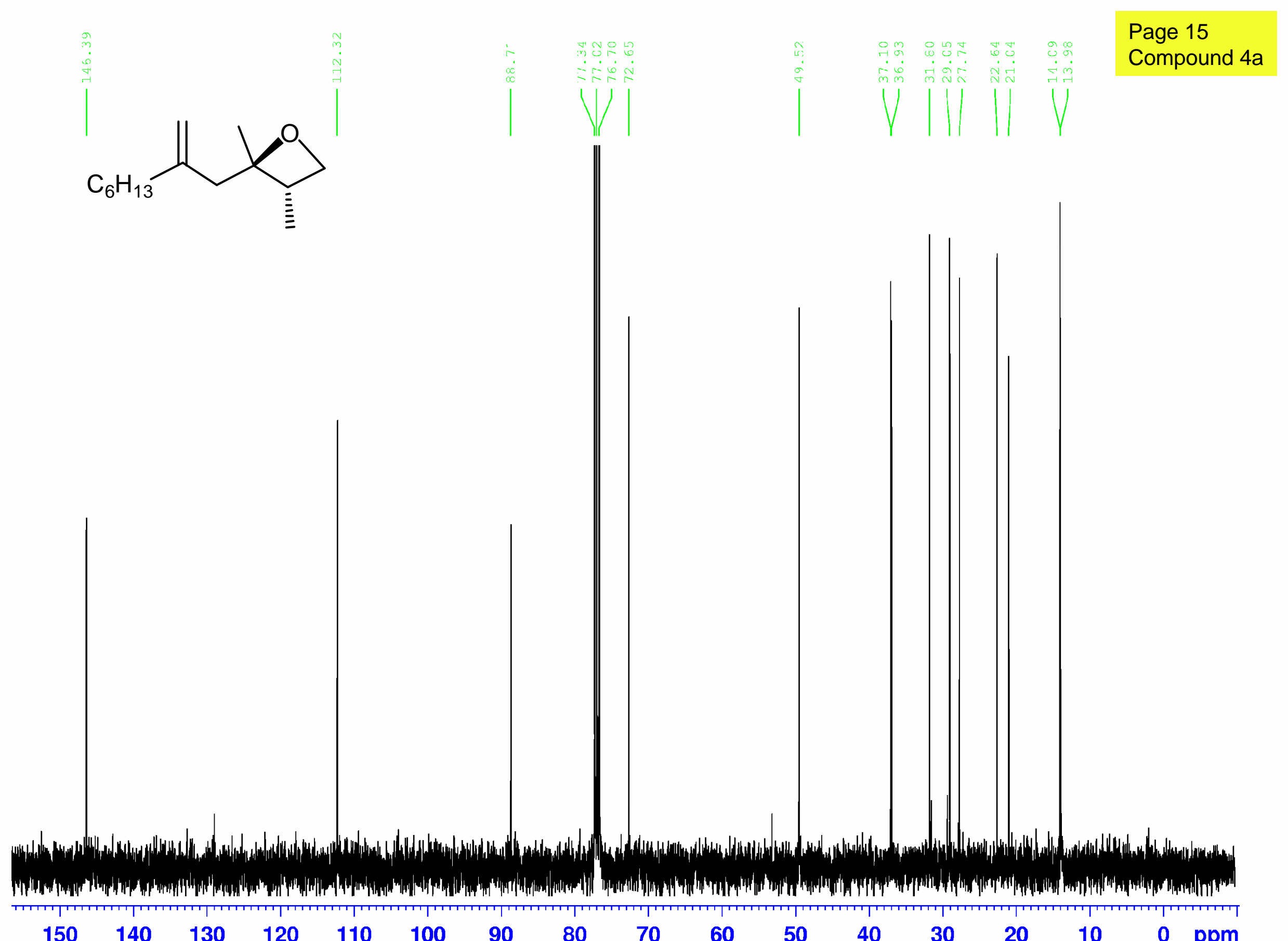



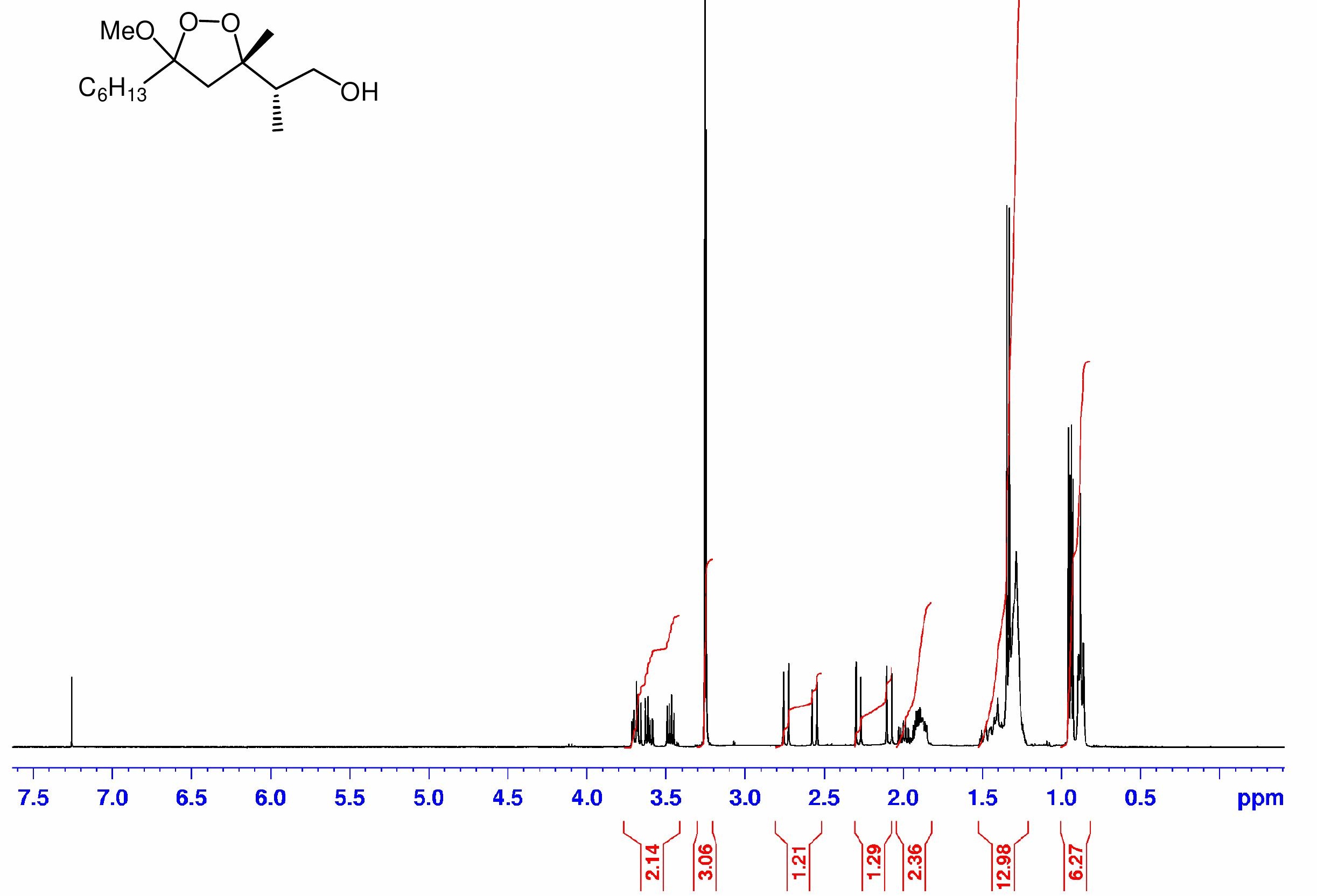


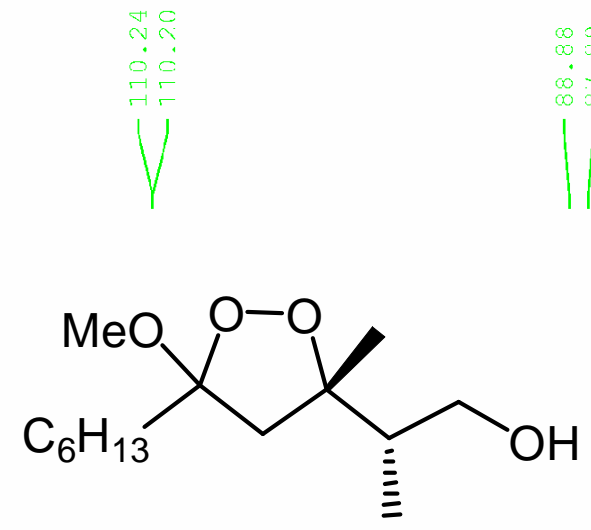



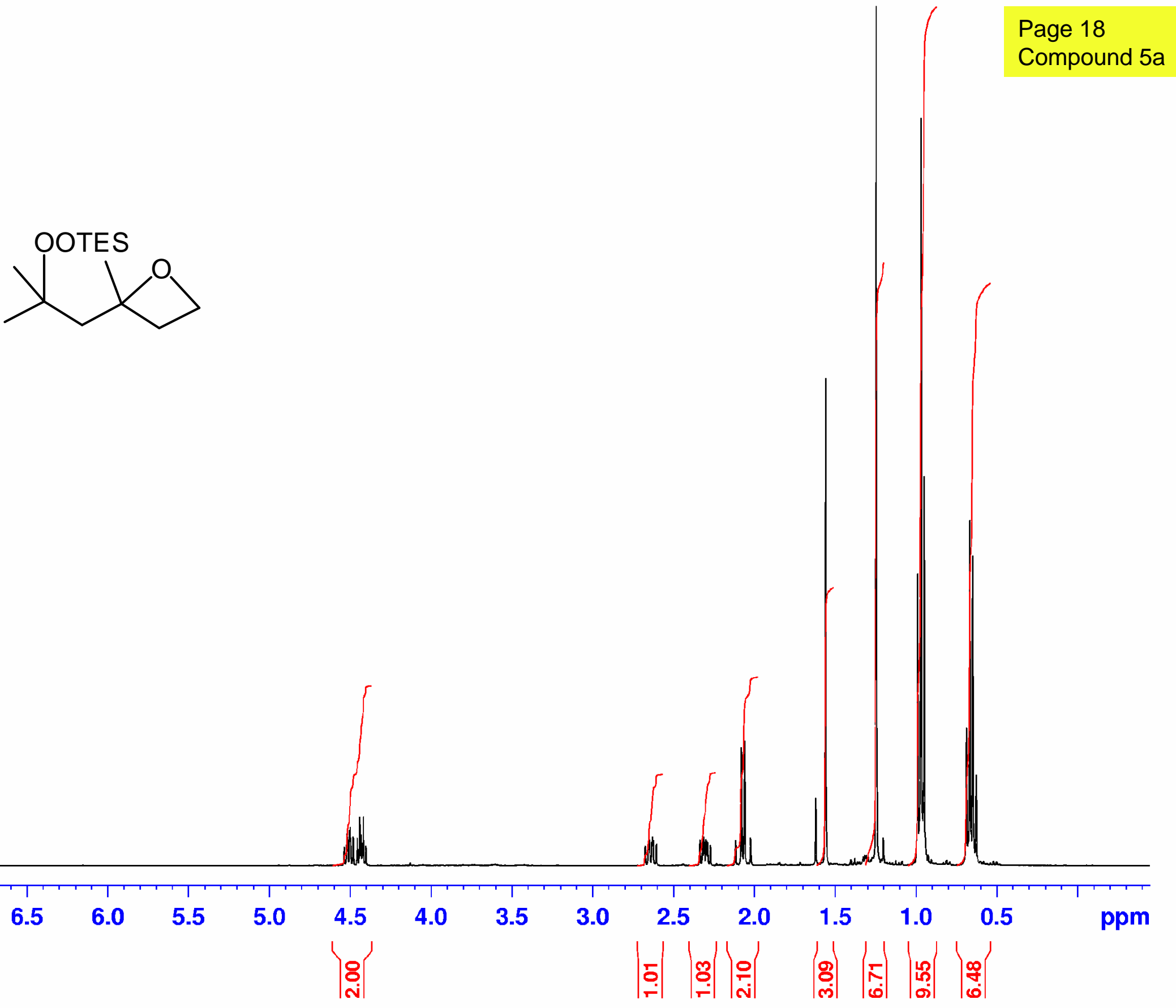

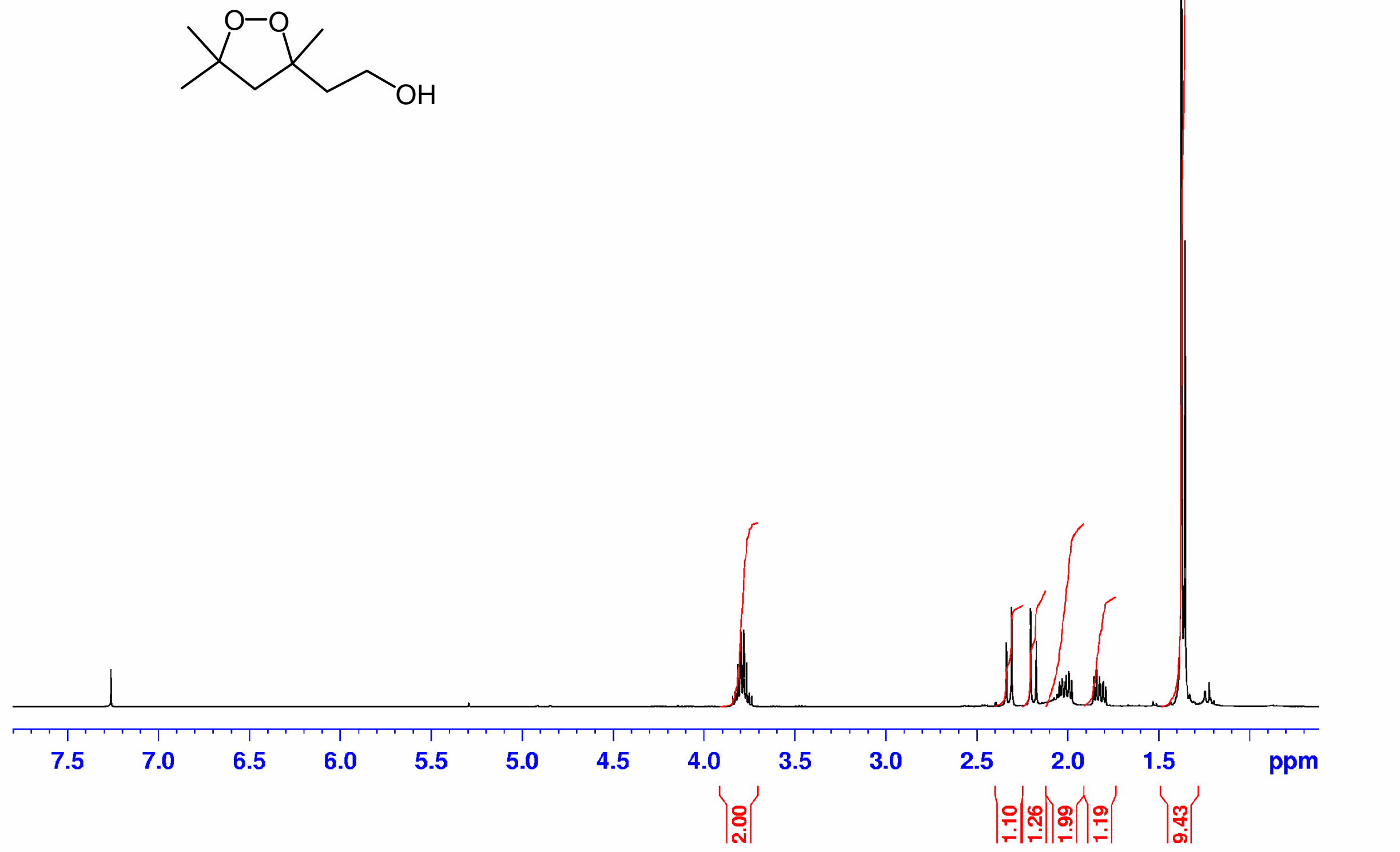


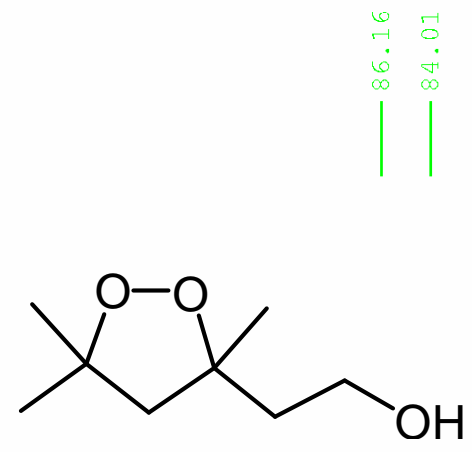

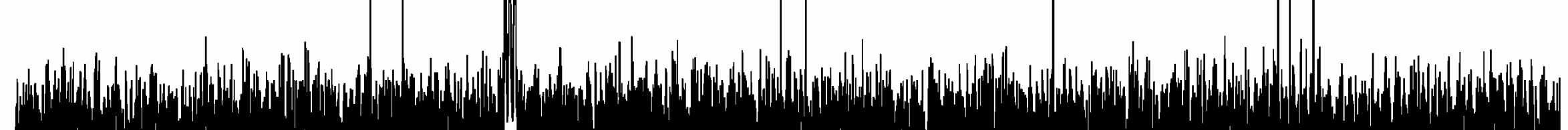

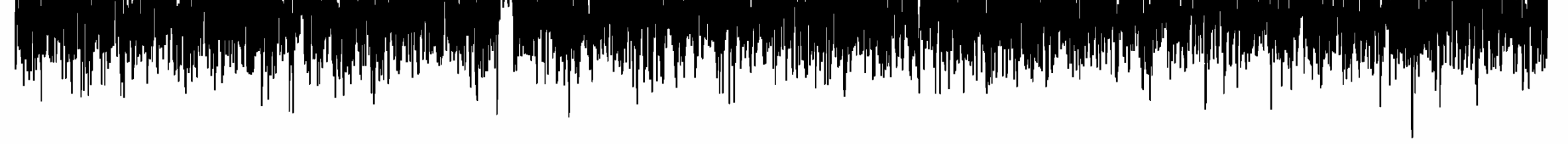

$\begin{array}{llllllllllllllllllll}105 & 100 & 95 & 90 & 85 & 80 & 75 & 70 & 65 & 60 & 55 & 50 & 45 & 40 & 35 & 30 & 25 & 20 & 15 & \mathrm{ppm}\end{array}$



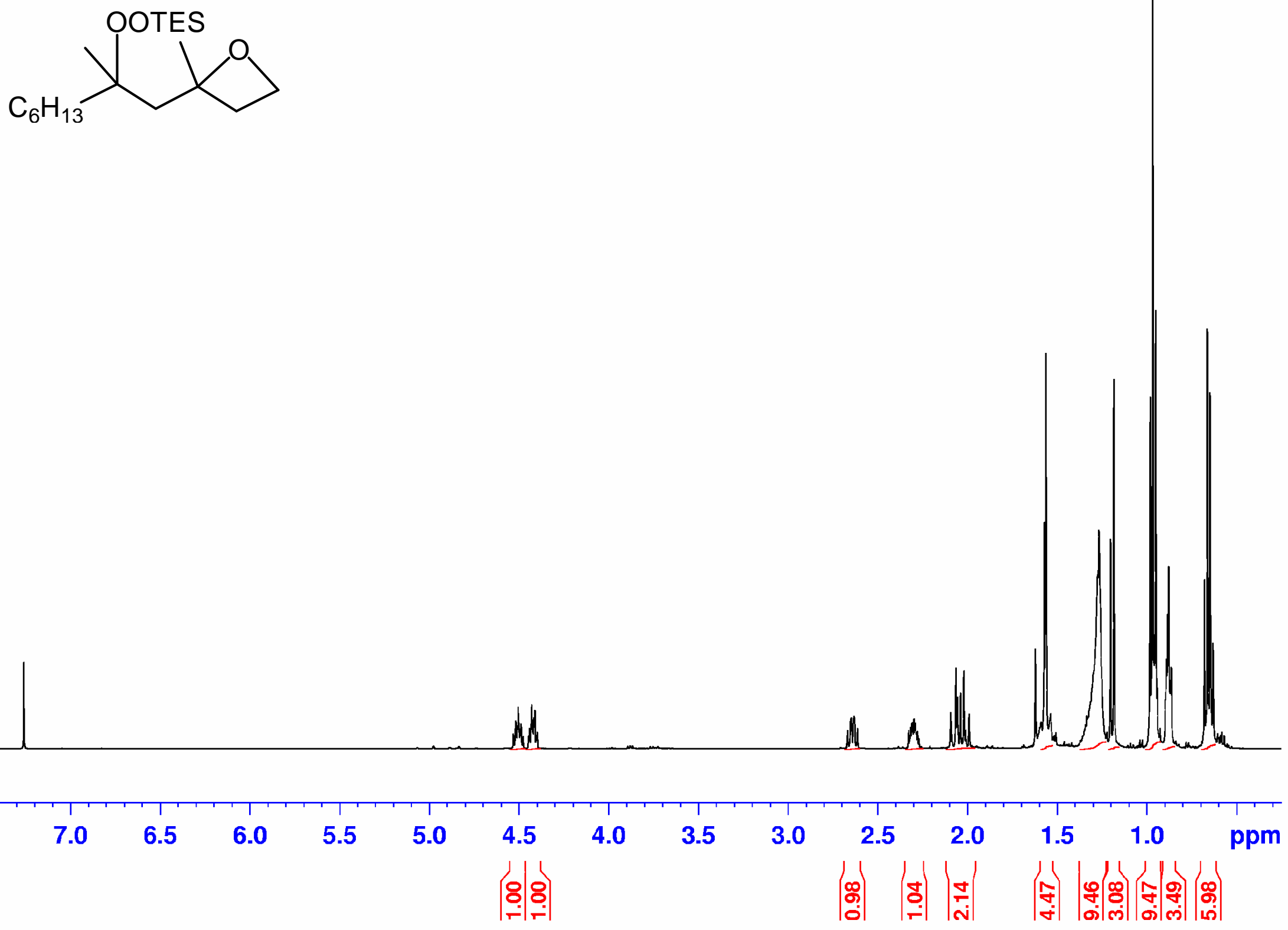
Page 23

Compound 6a

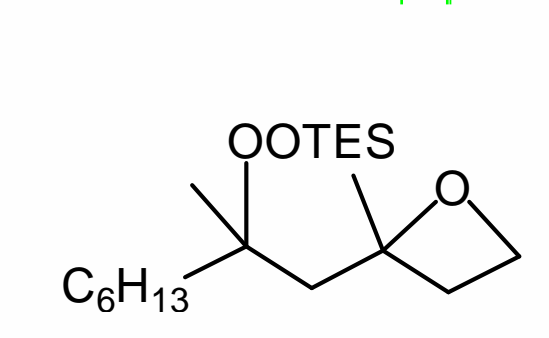




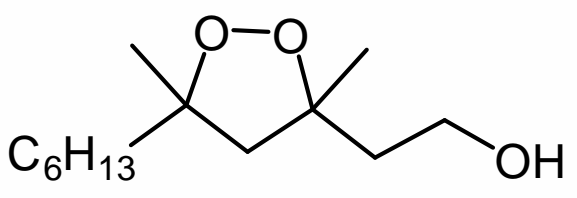

cis-isomer

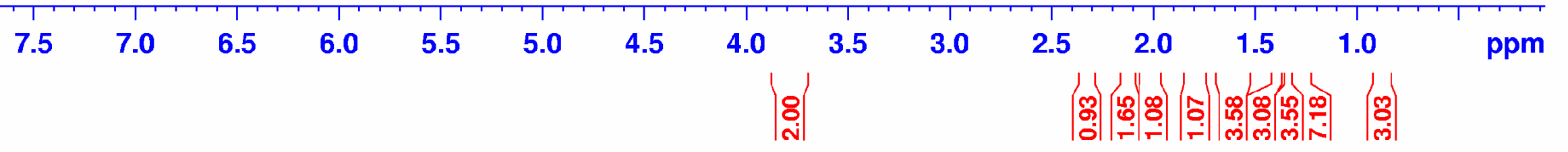




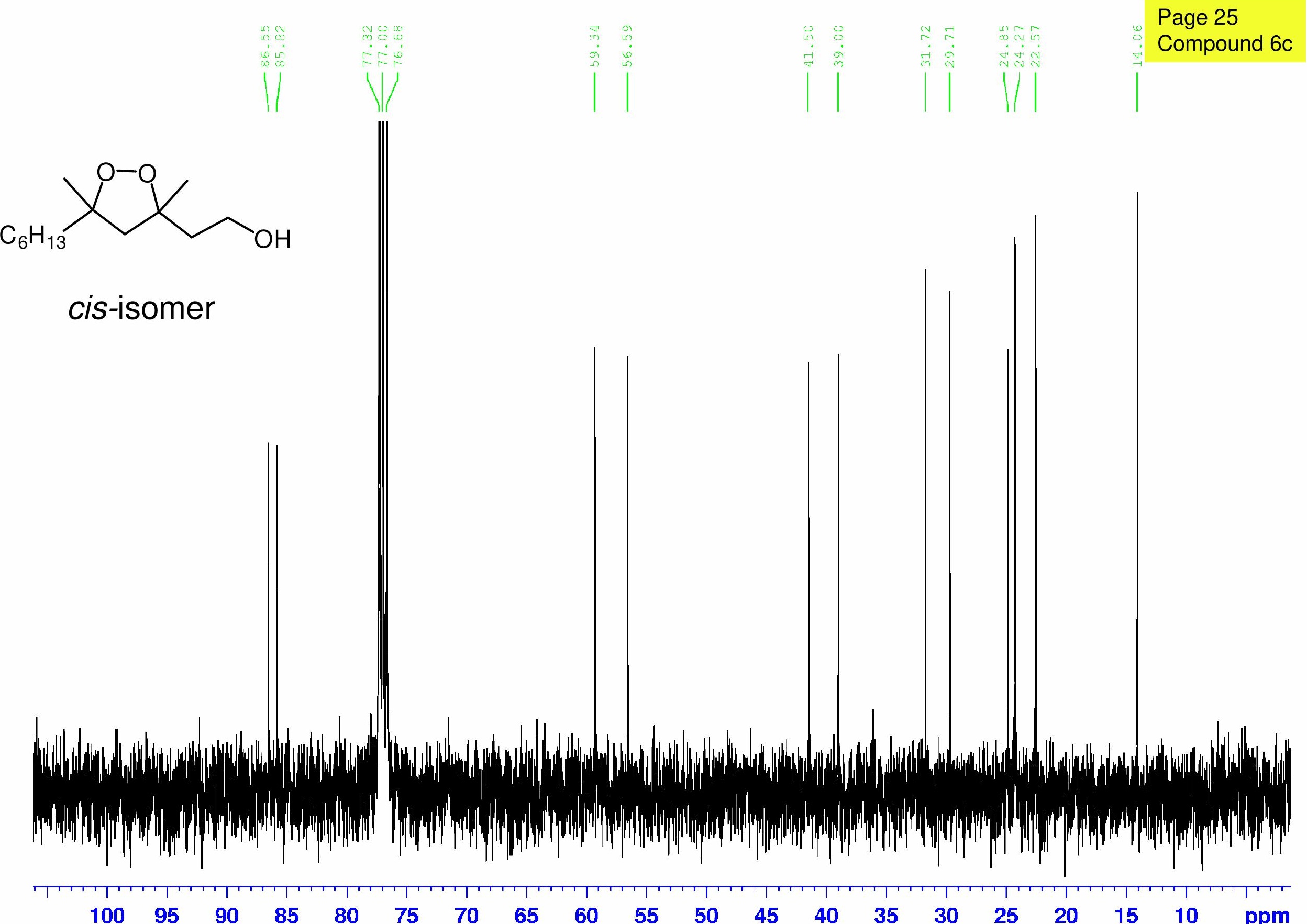




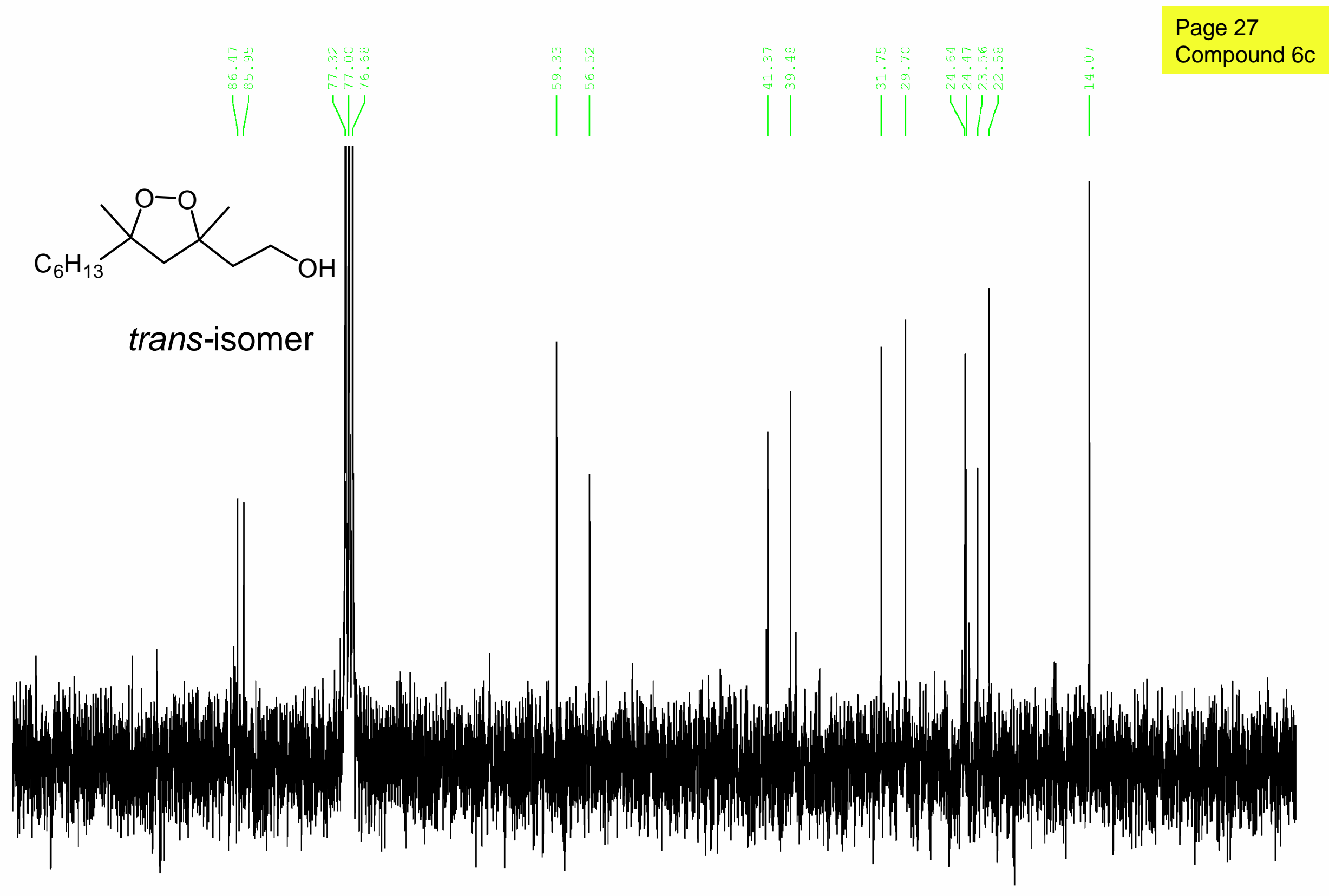
$\begin{array}{lllllllllllllllllllll}100 & 95 & 90 & 85 & 80 & 75 & 70 & 65 & 60 & 55 & 50 & 45 & 40 & 35 & 30 & 25 & 20 & 15 & 10 & 5 & \text { ppm }\end{array}$ 


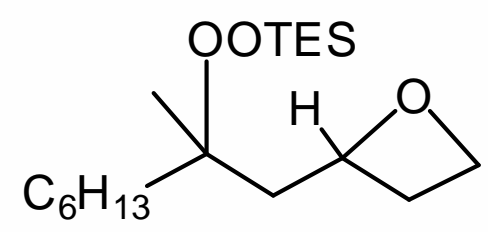

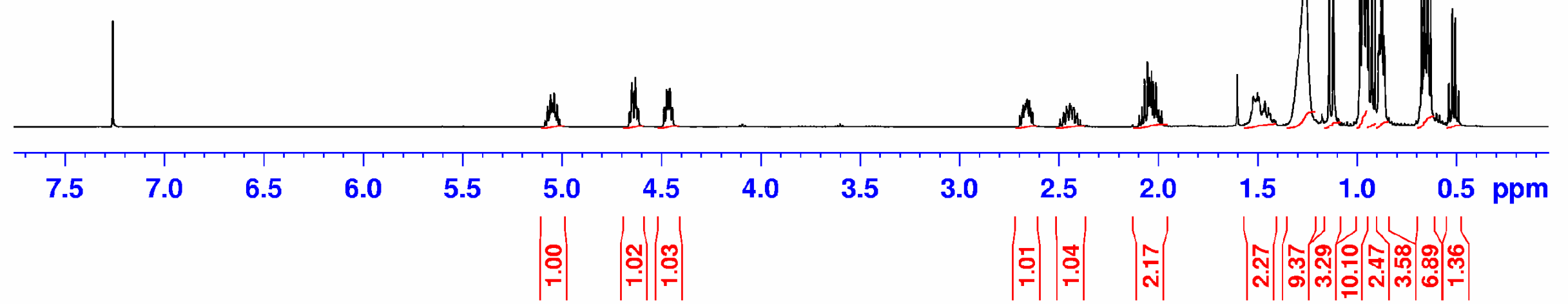


<smiles>CC1([15CH2])CC(CCO)OO1</smiles>

\section{cis-isomer}

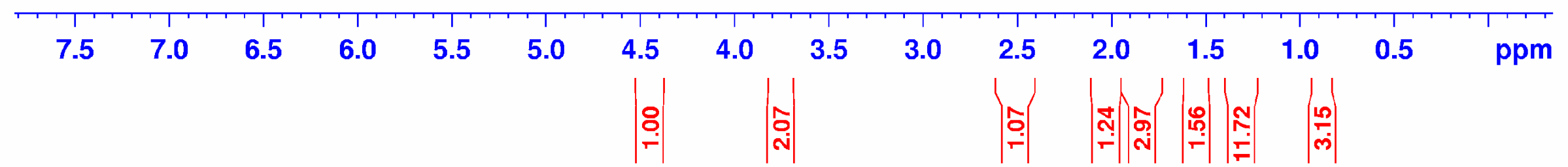




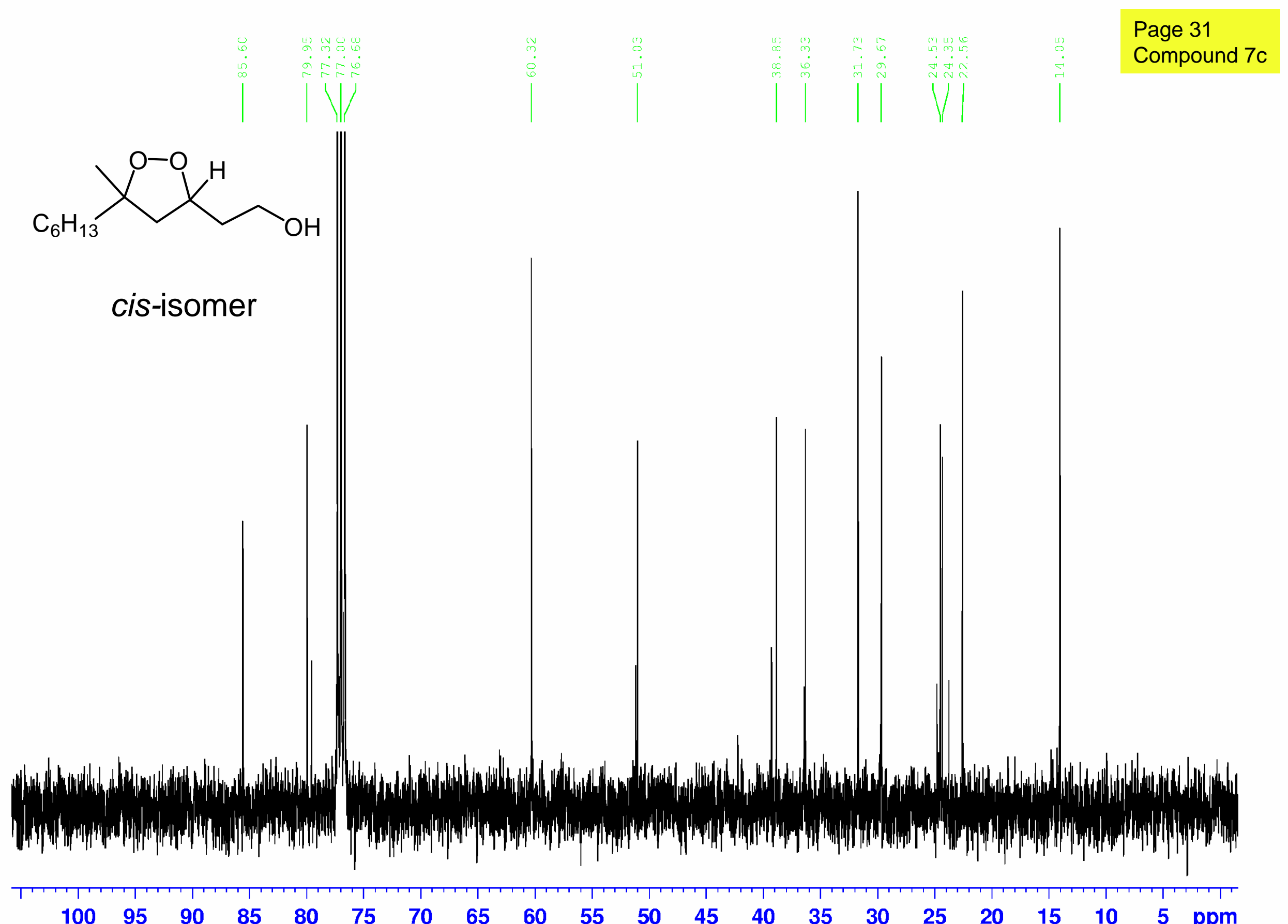




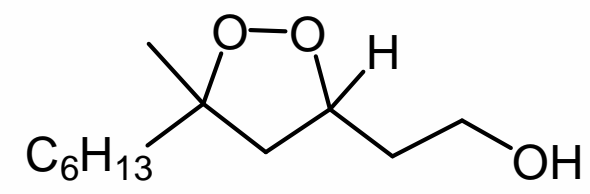

trans-isomer
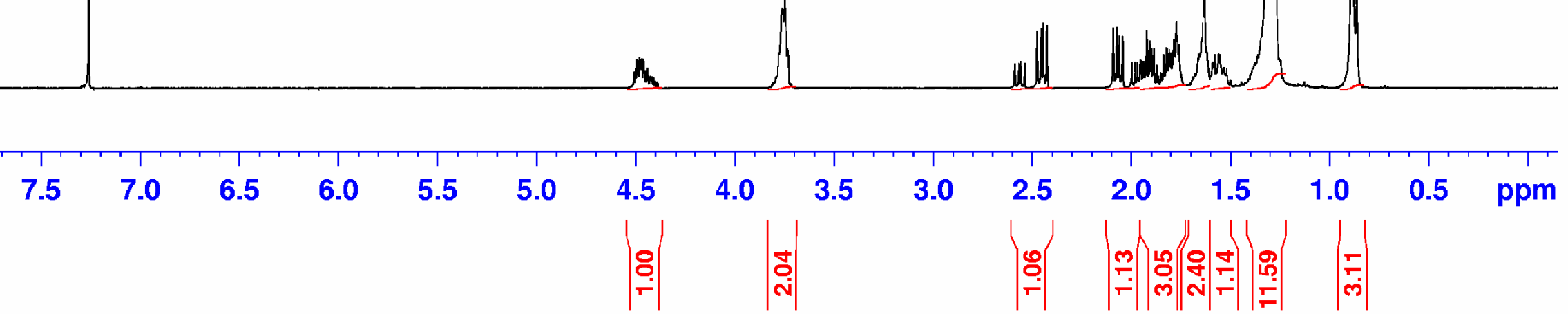


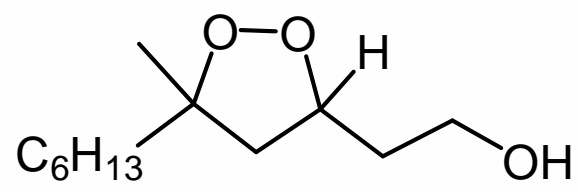

cis-isomer
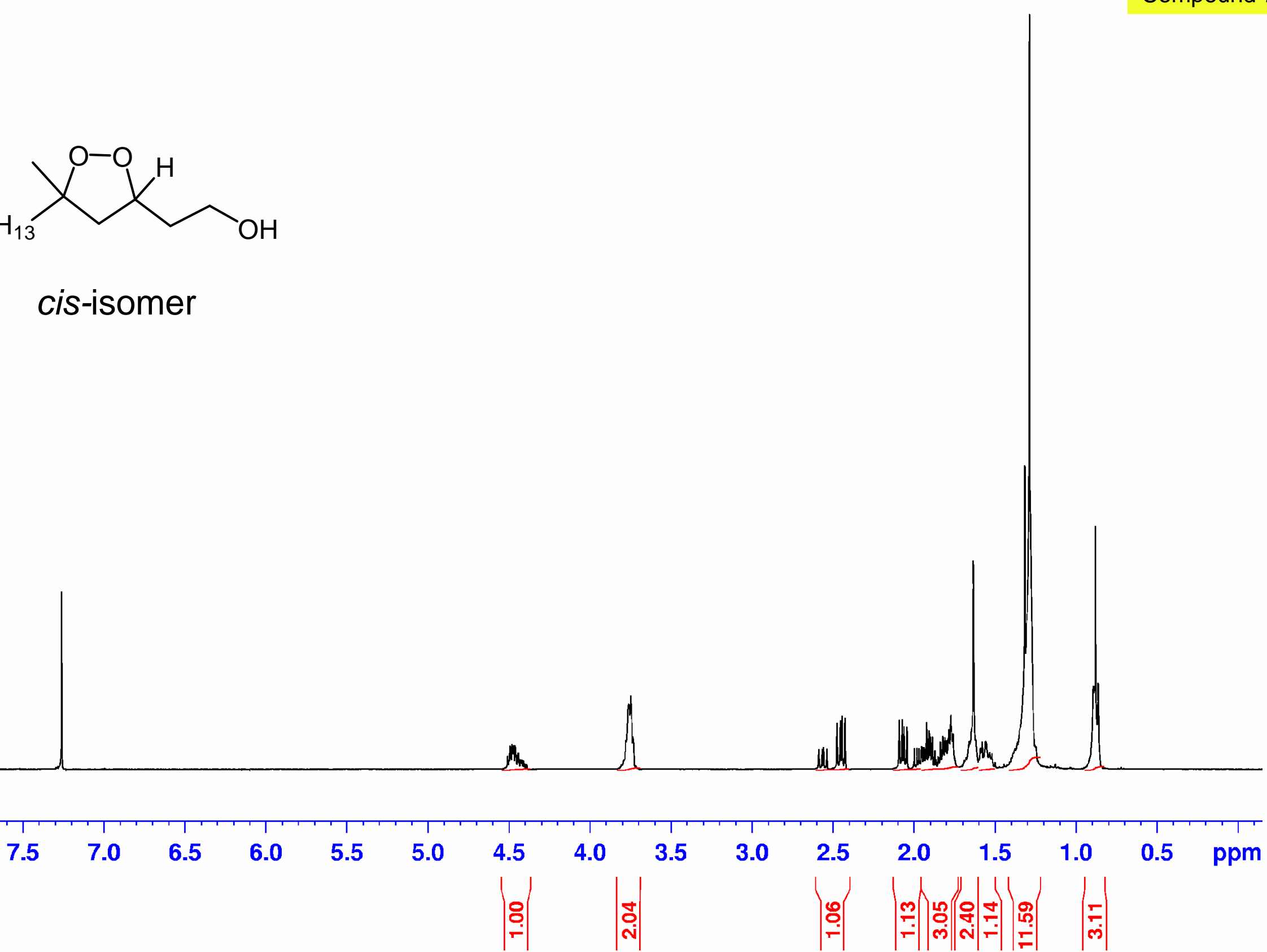


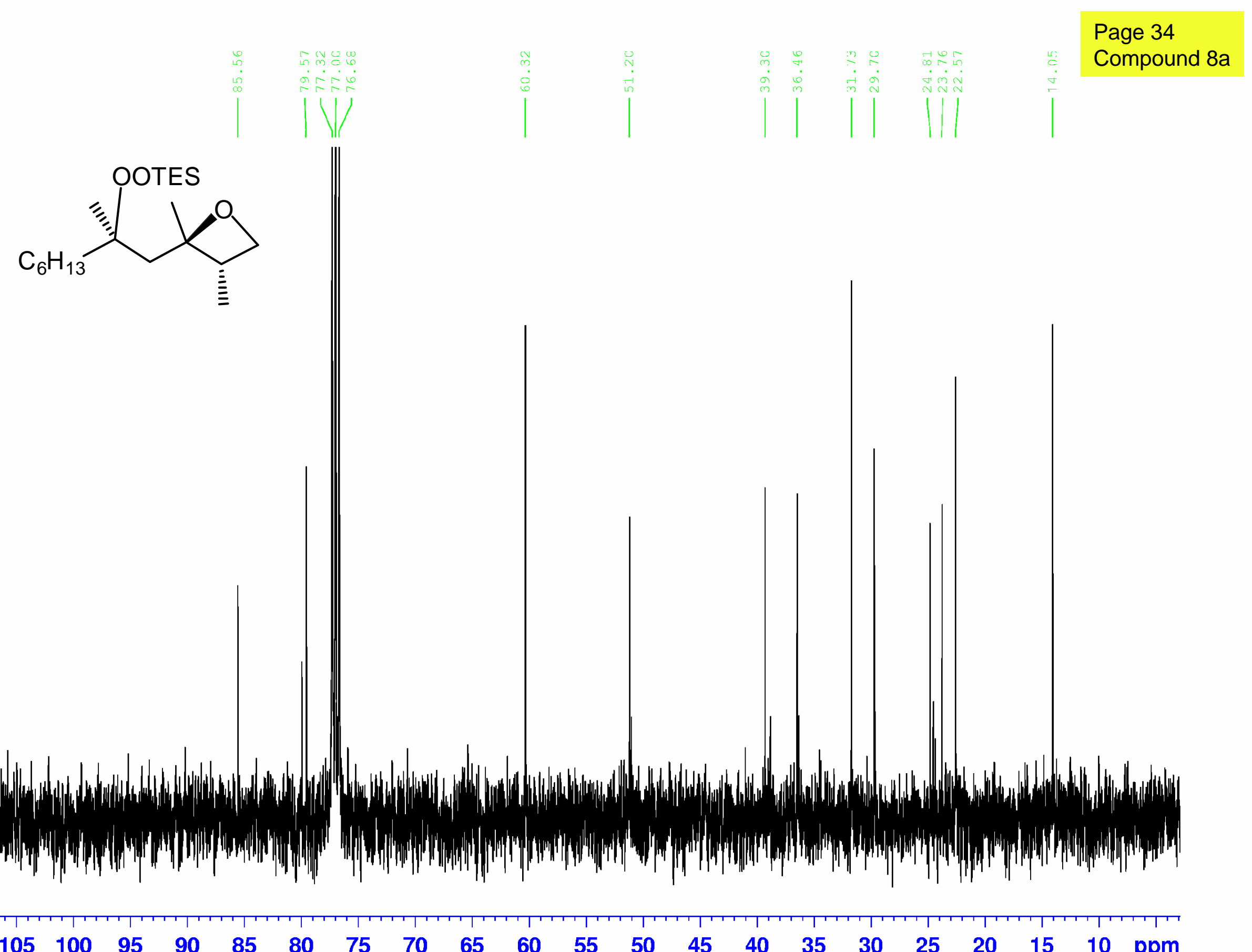



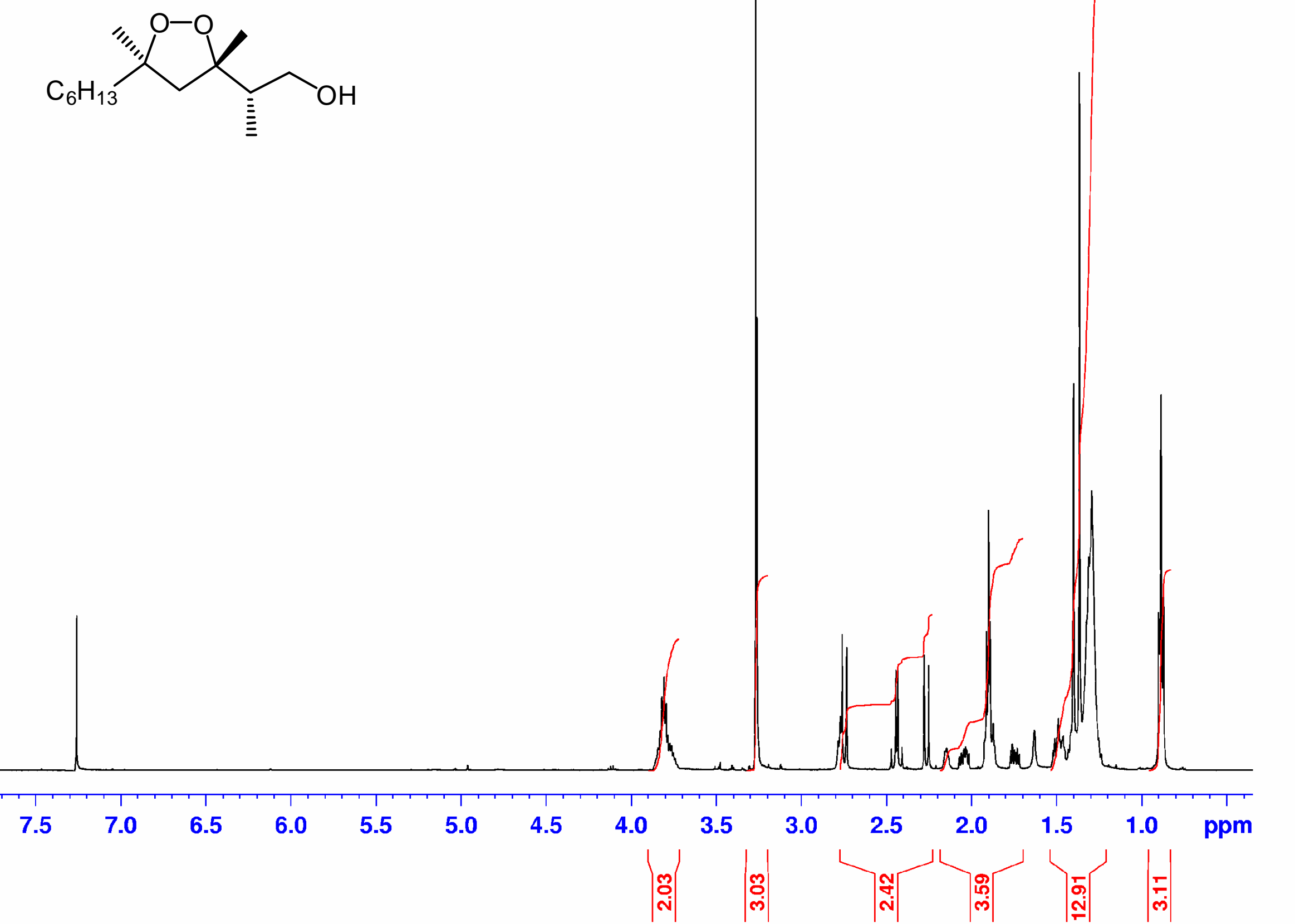


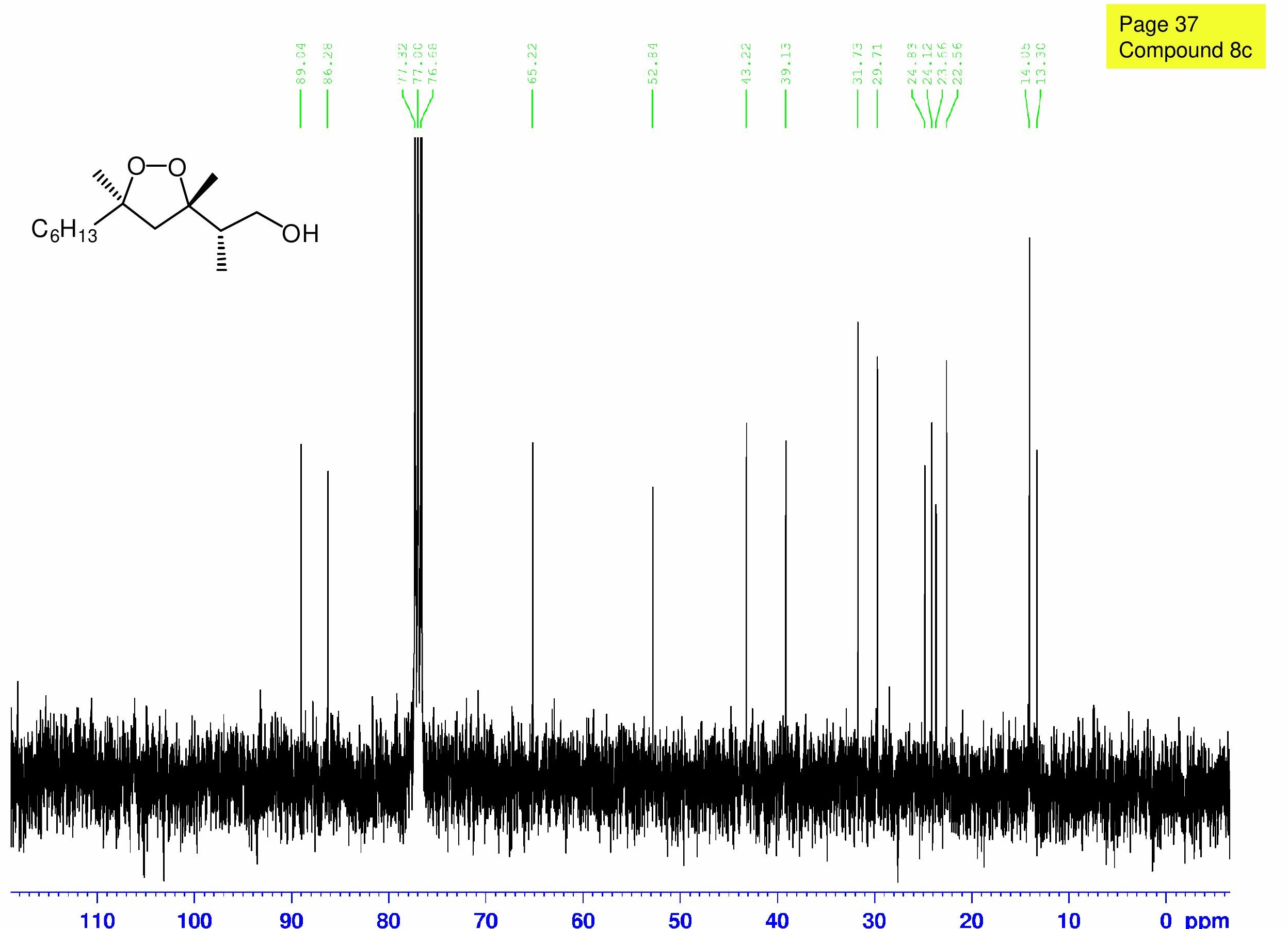



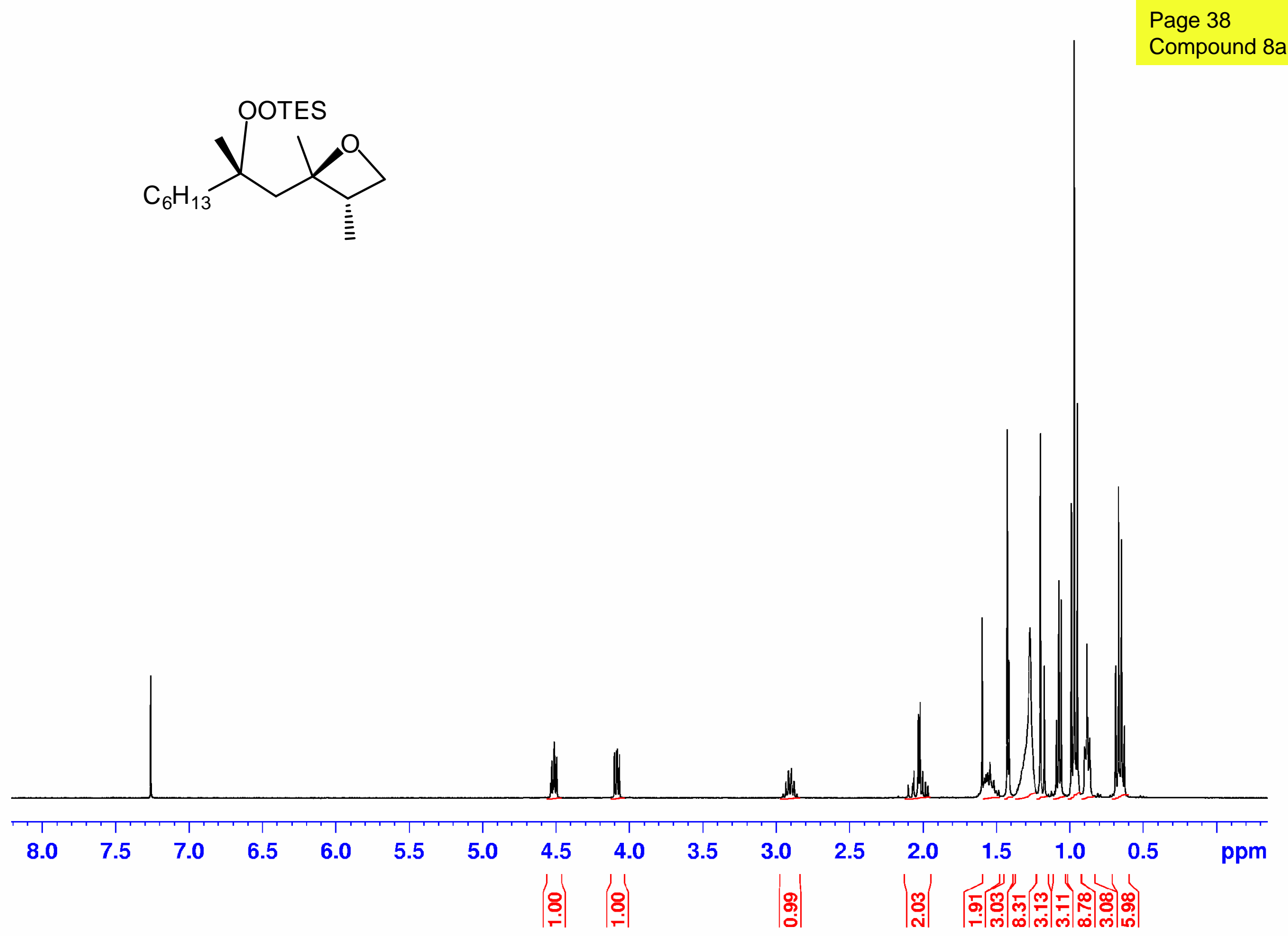


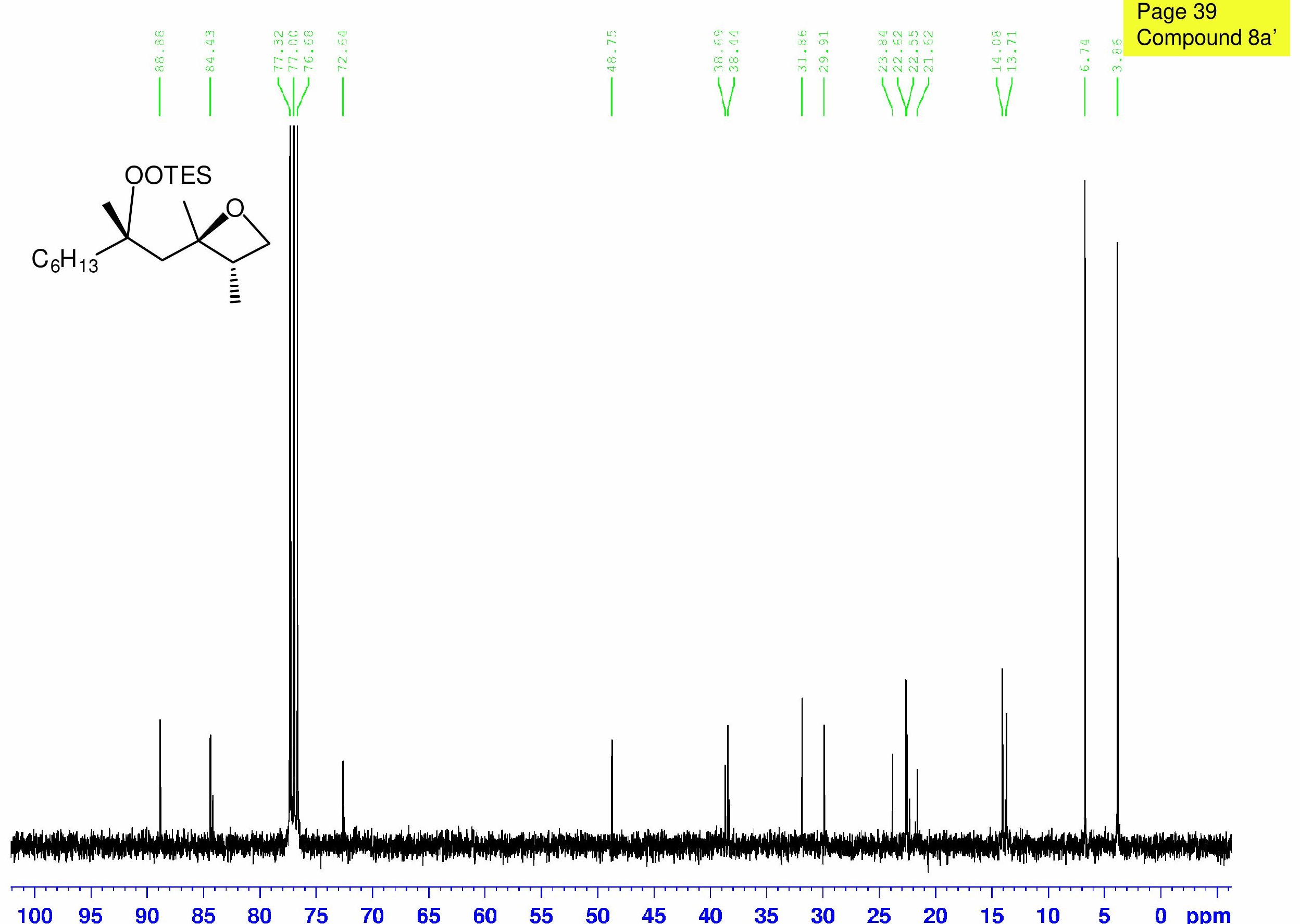




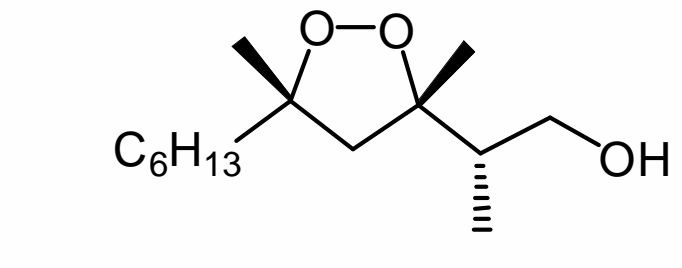

Page 40

Compound Bc'

\begin{tabular}{lllllllllllllllllllllll}
\hline 8.0 & 7.5 & 7.0 & 6.5 & 6.0 & 5.5 & 5.0 & 4.5 & 4.0 & 3.5 & 3.0 & 2.5 & 2.0 & 1.5 & 1.0 & 0.5 & 0.0 & $\mathrm{ppm}$
\end{tabular}

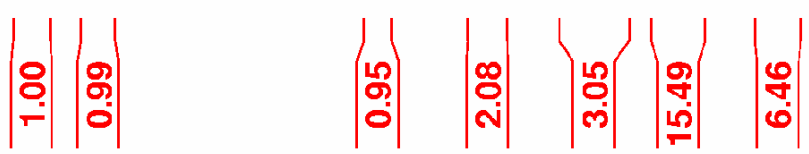




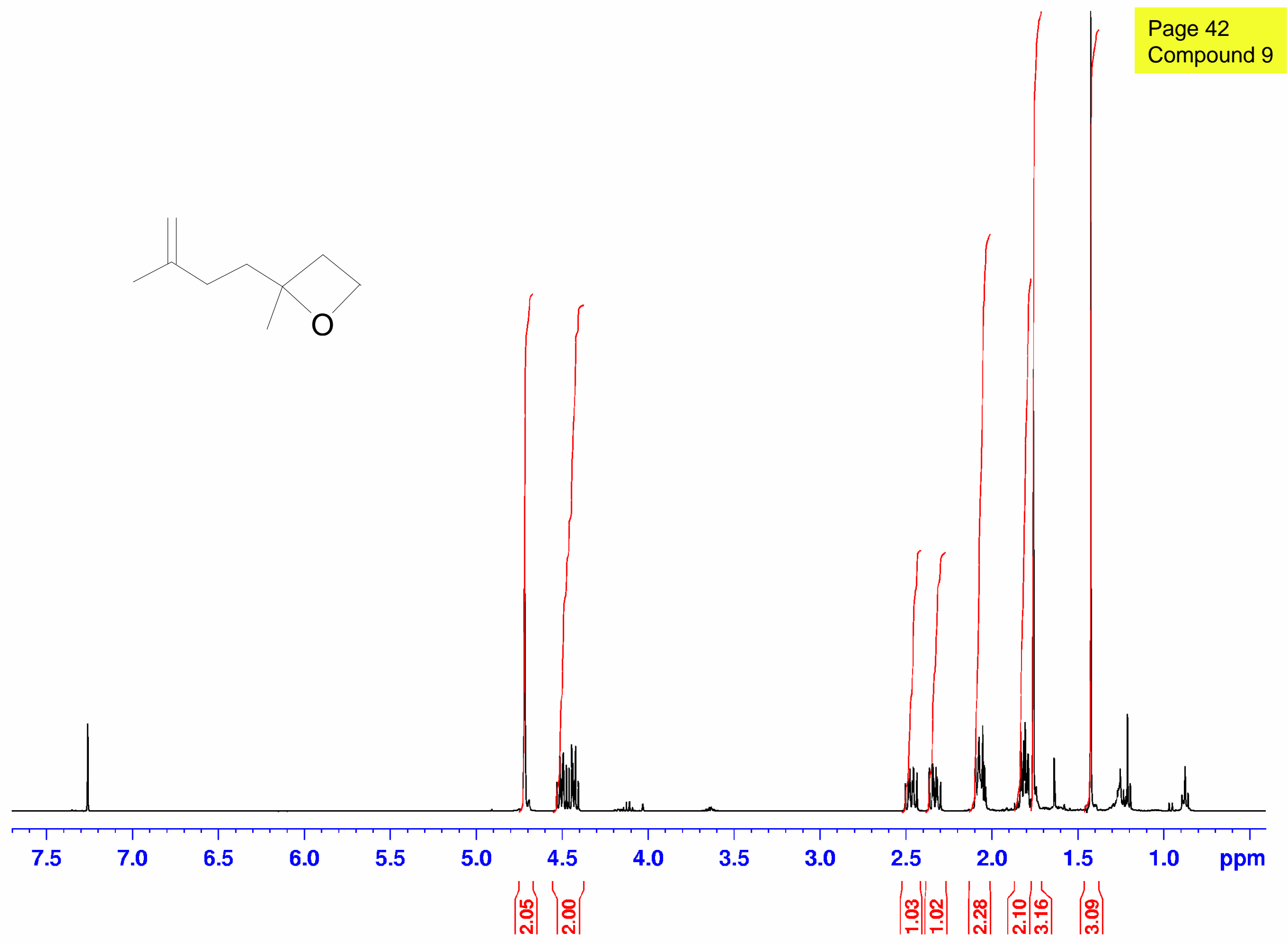




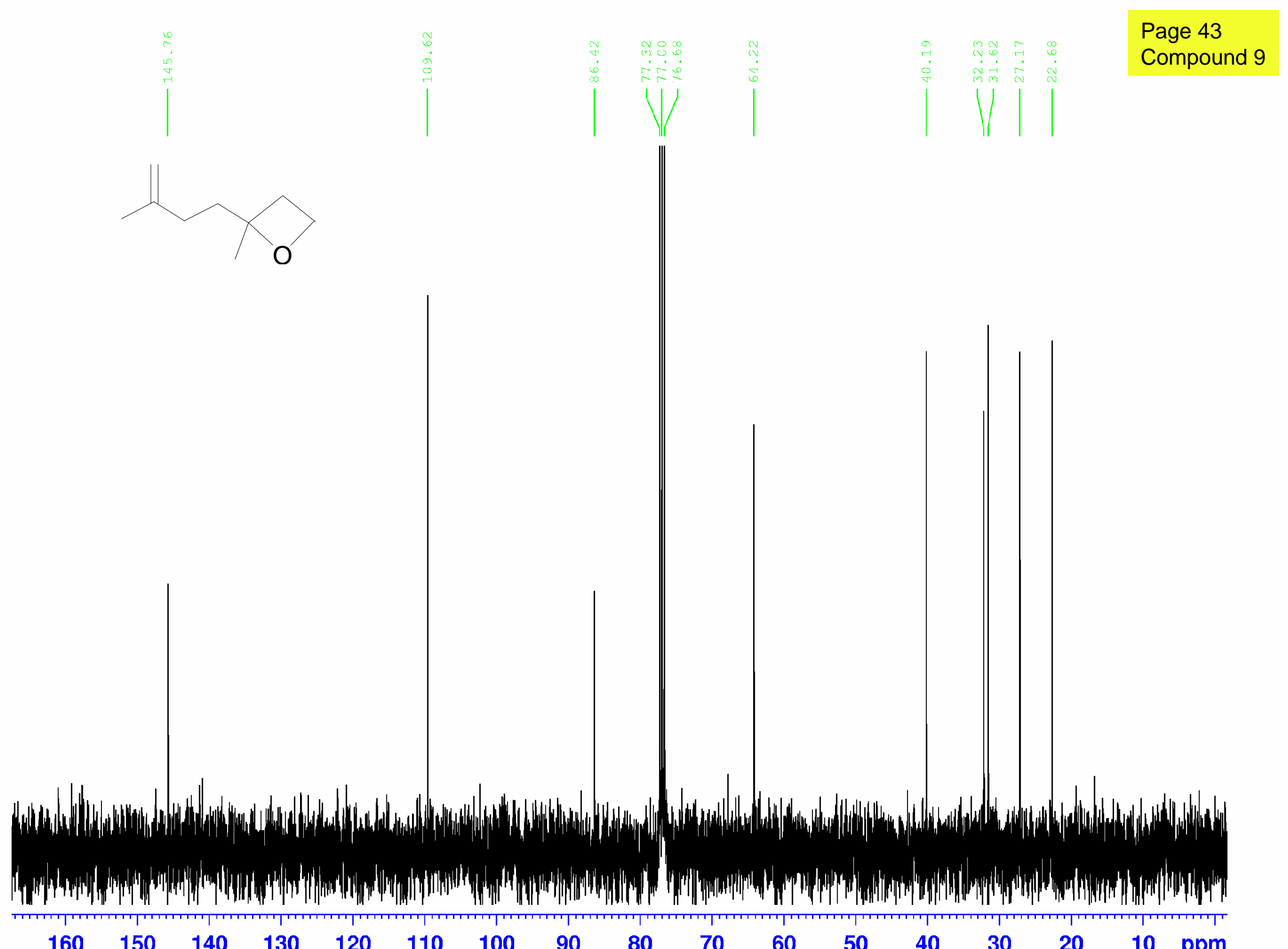




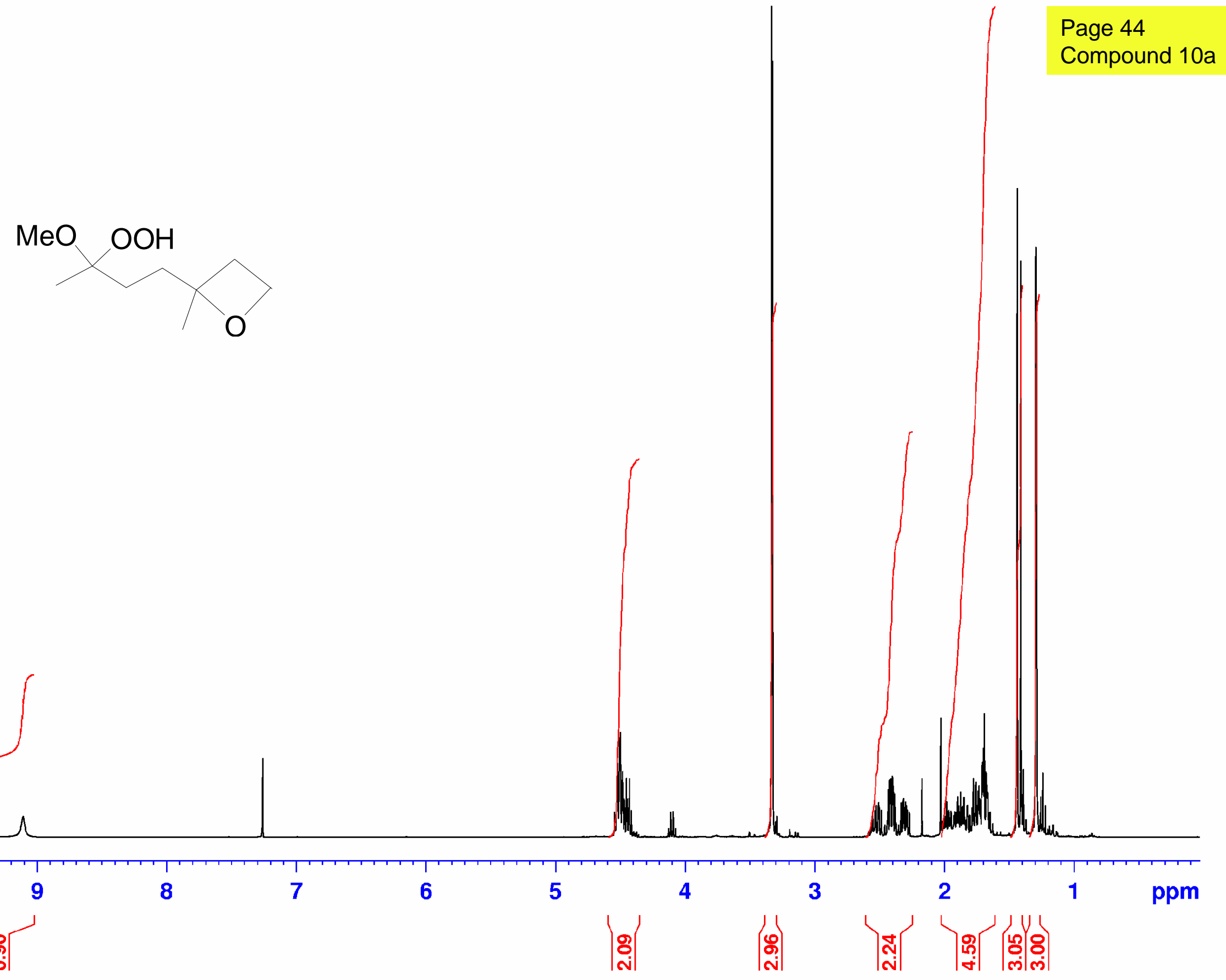




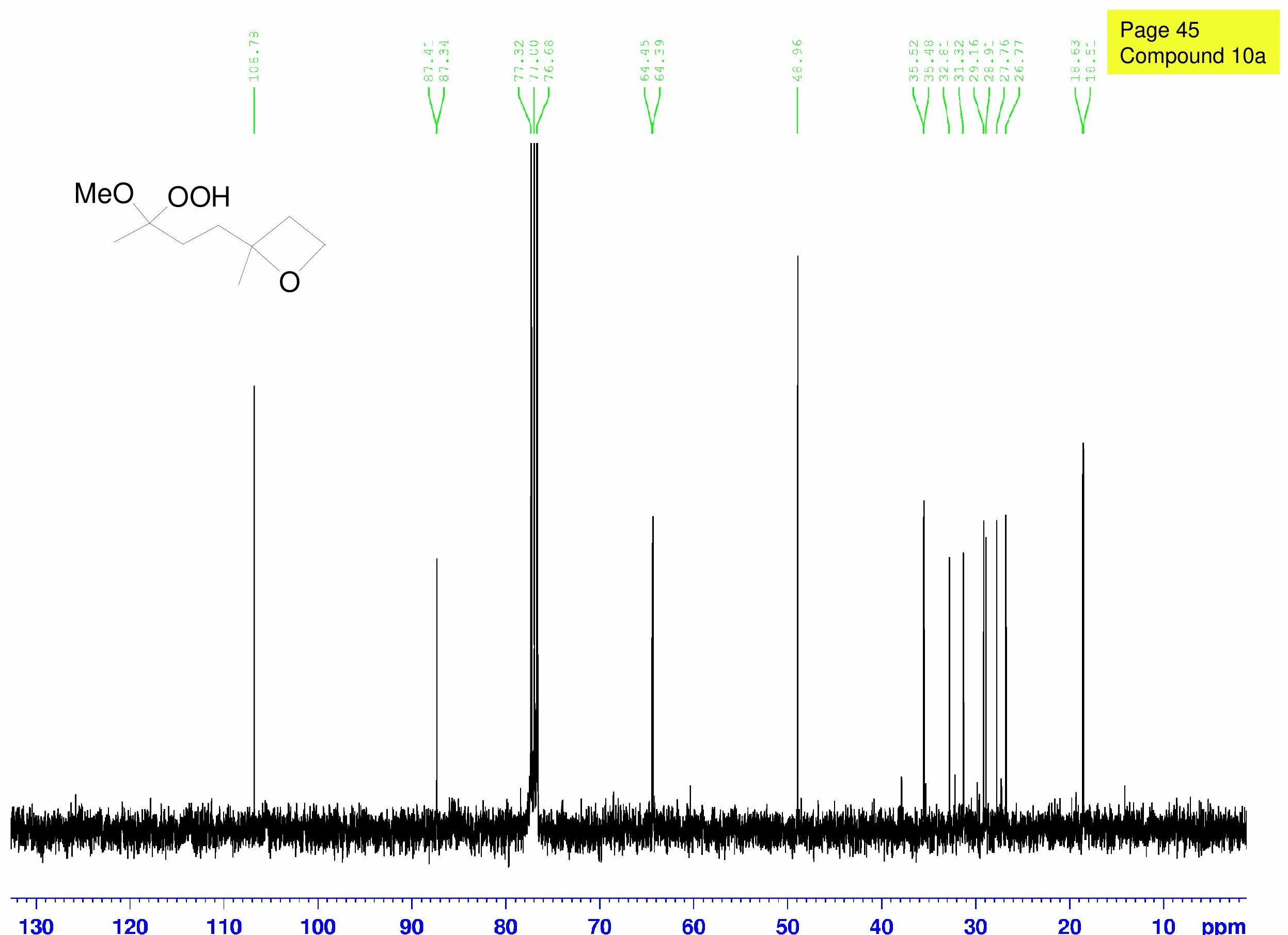




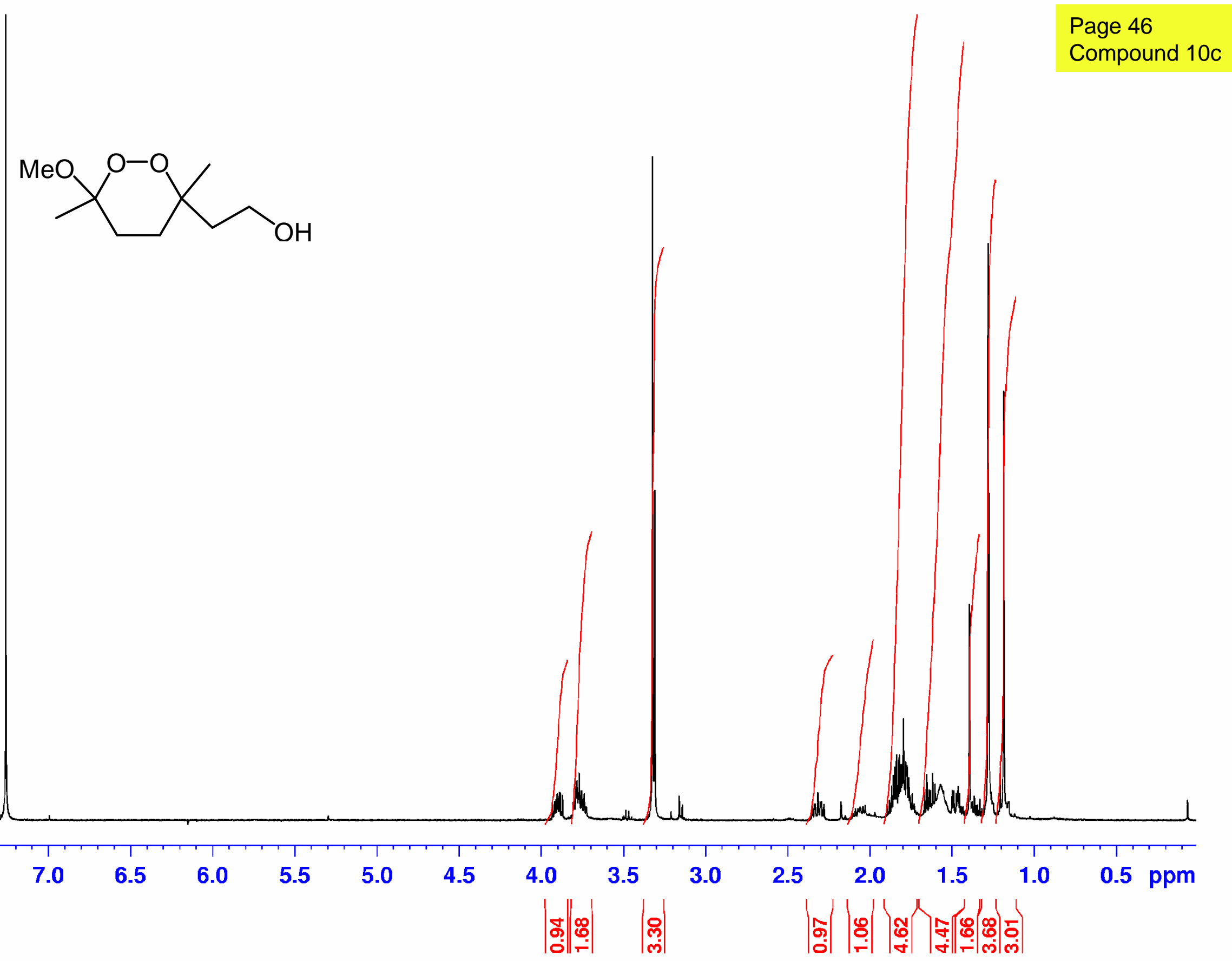



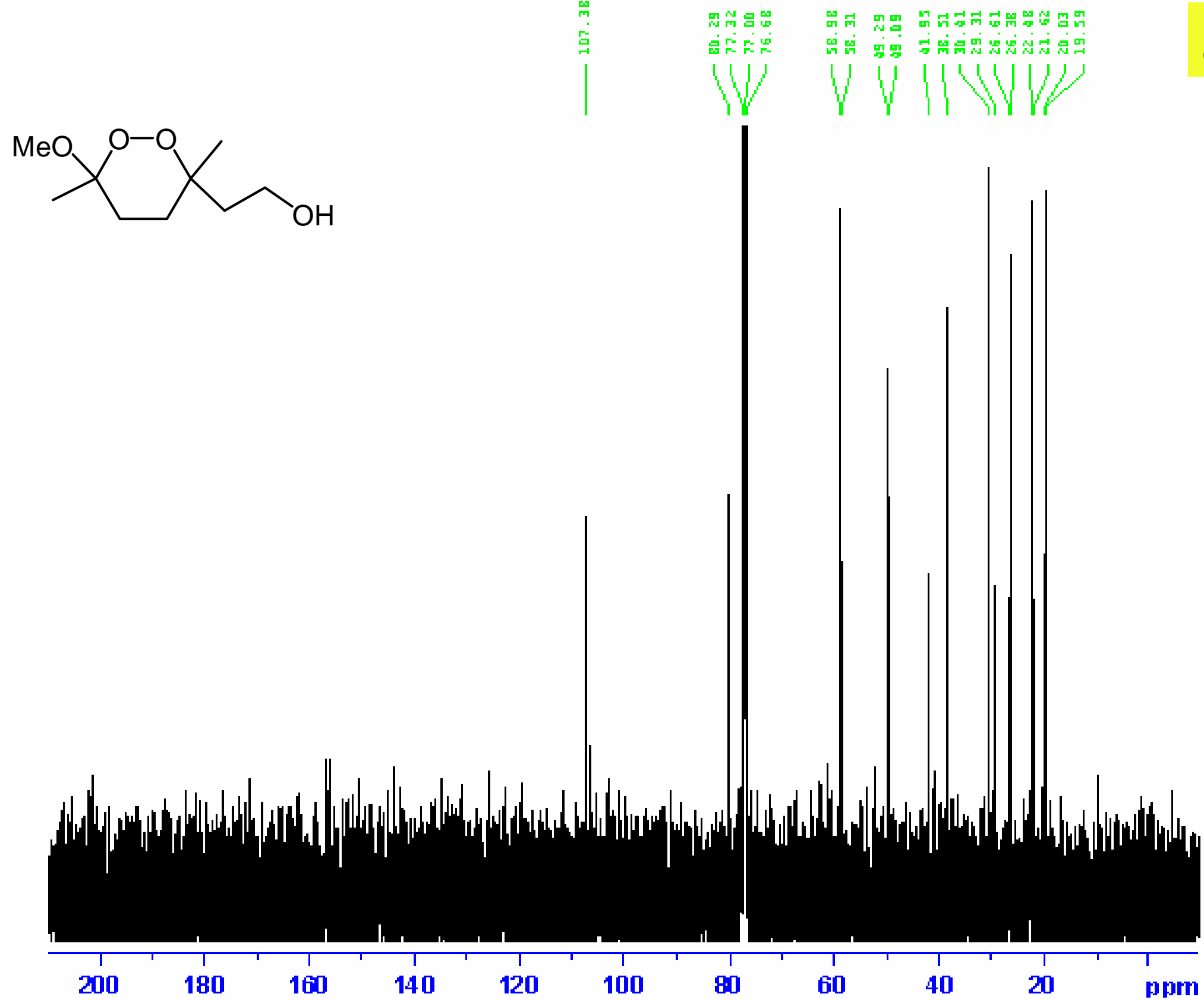


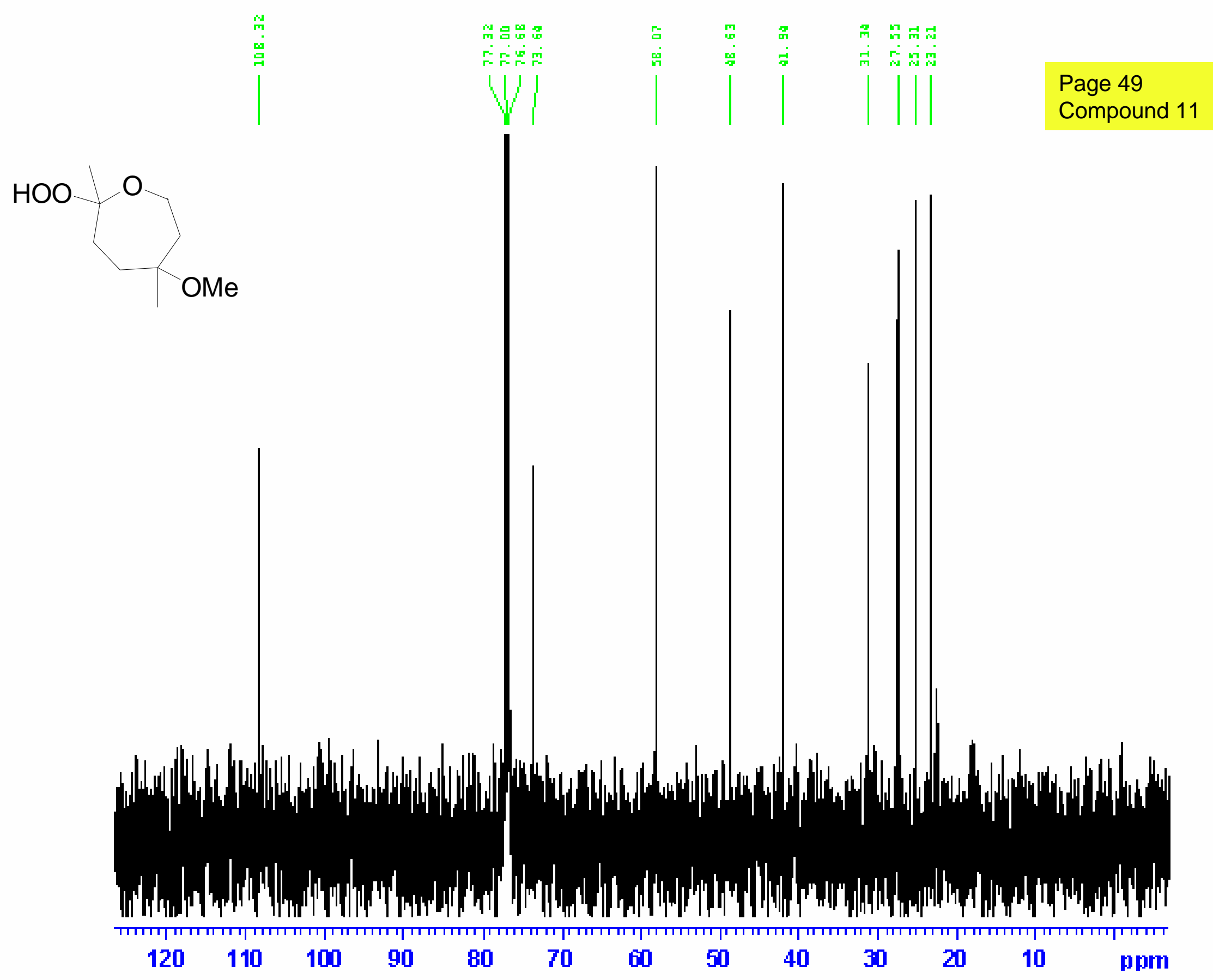


OOTES

0

Page 50

Compound 12a

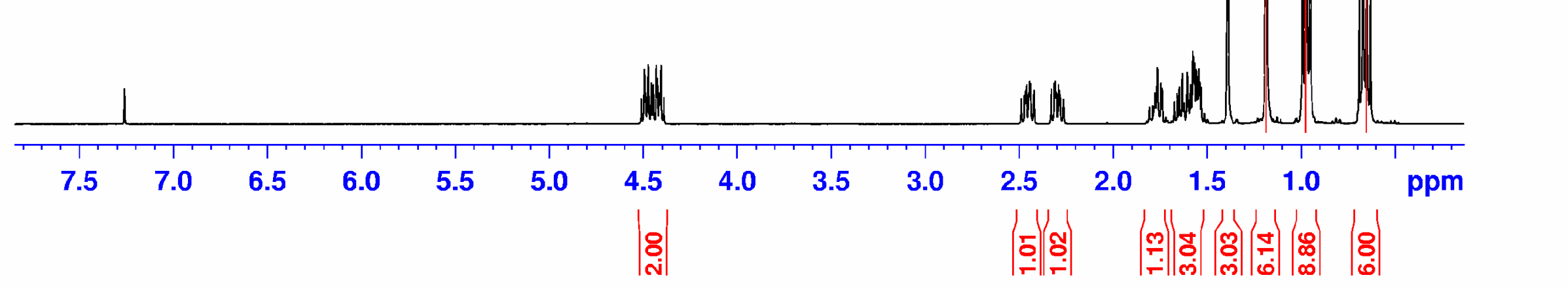


Page 52

Compound 12c

\section{$\mathrm{OH}$}

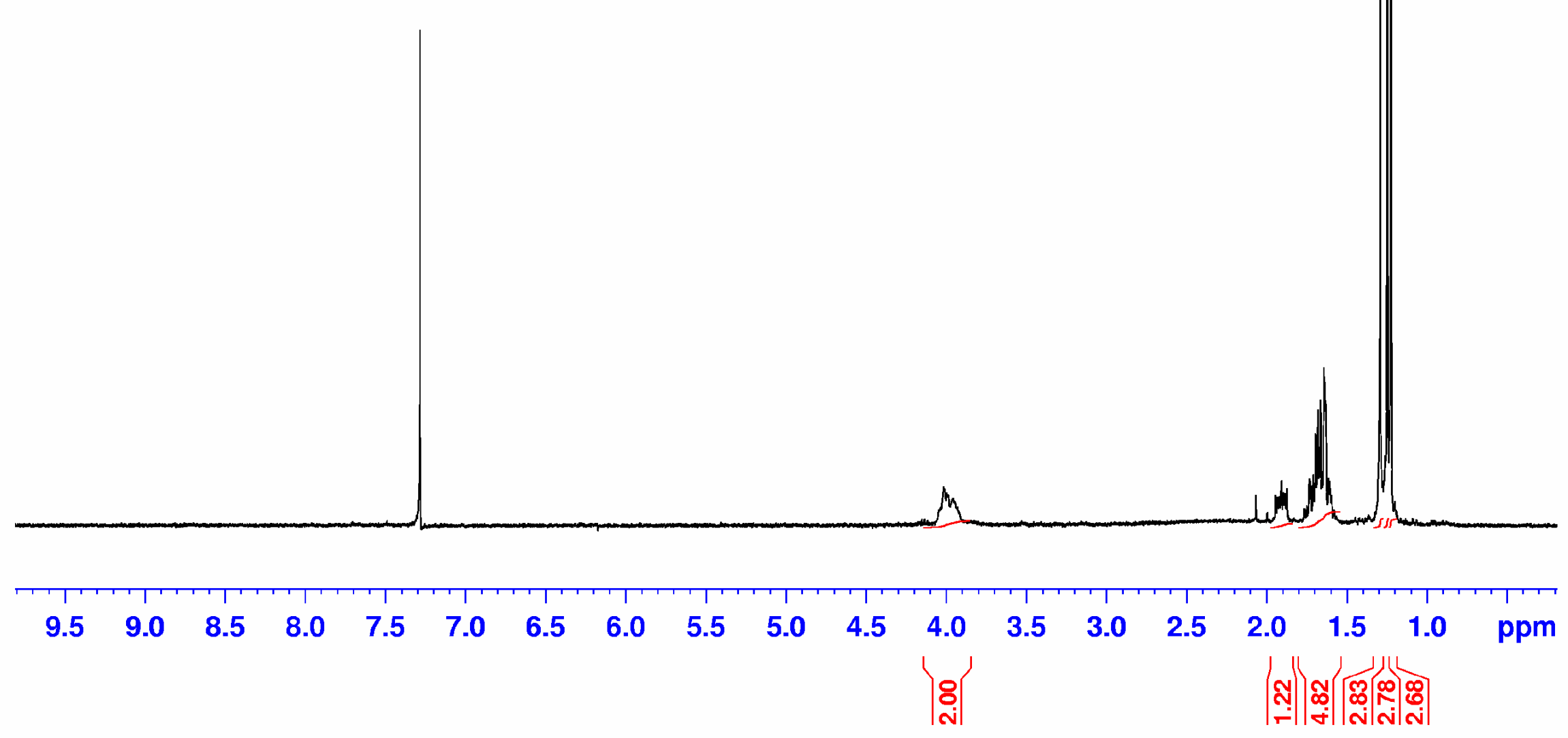




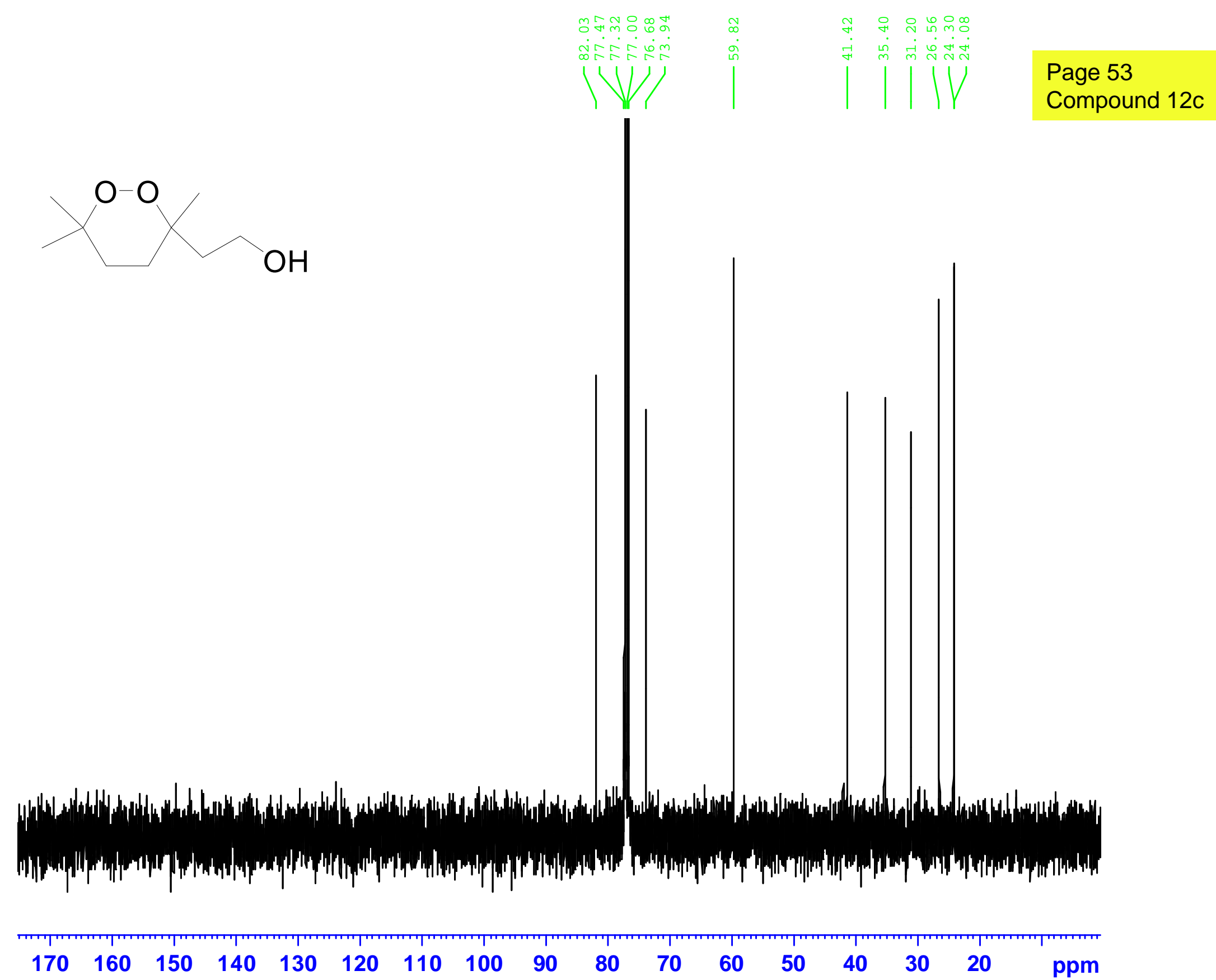




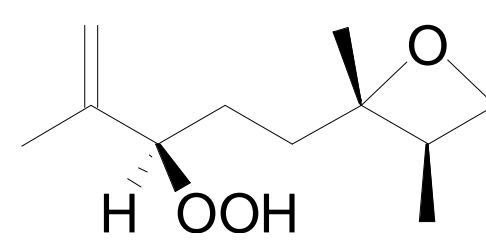

Page 54

Compound 13a

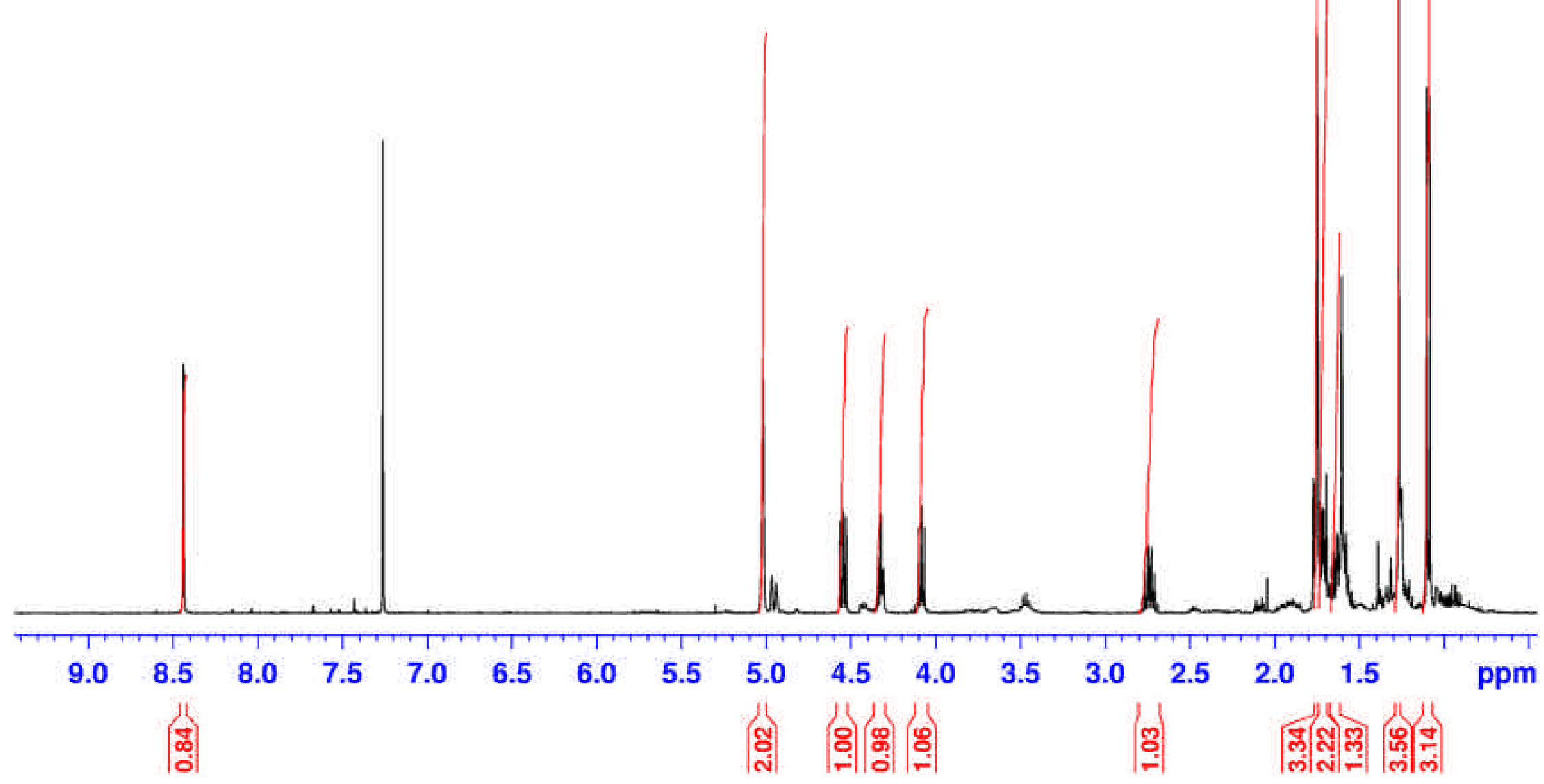




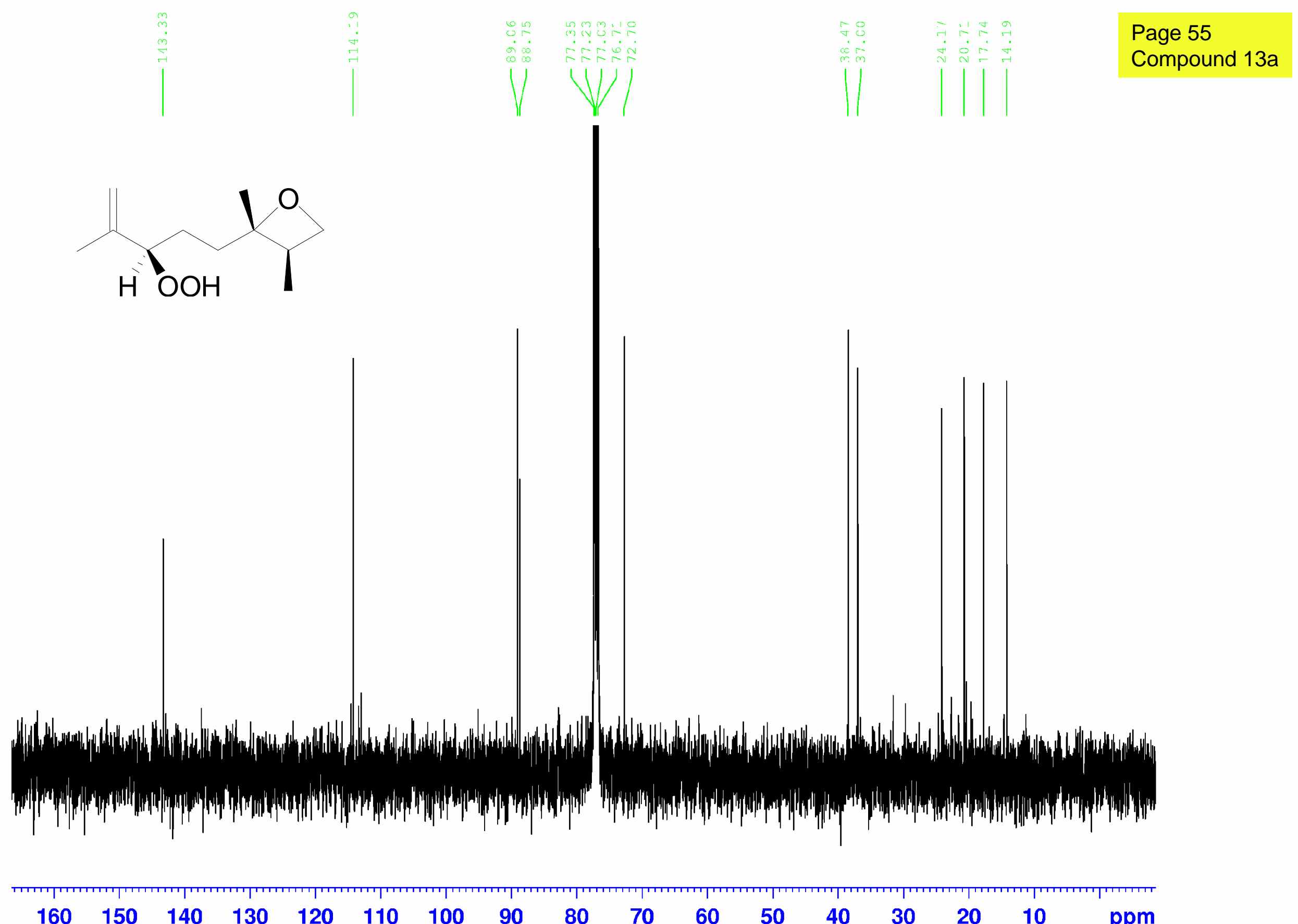


Page 56

Compound 14

$\mathrm{OOH} \quad 1 \mathrm{O}$ I

8

7

6

5

4

$\mid$

$\left|\begin{array}{l}0 \\ 0 \\ -1\end{array}\right|$

$\left|\begin{array}{l}8 \\ 8 \\ \hdashline\end{array}\right|\left|\begin{array}{l}10 \\ 0 \\ \text { in }\end{array}\right|$

2

1

o ppm

ఫ্

|

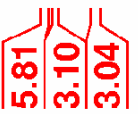




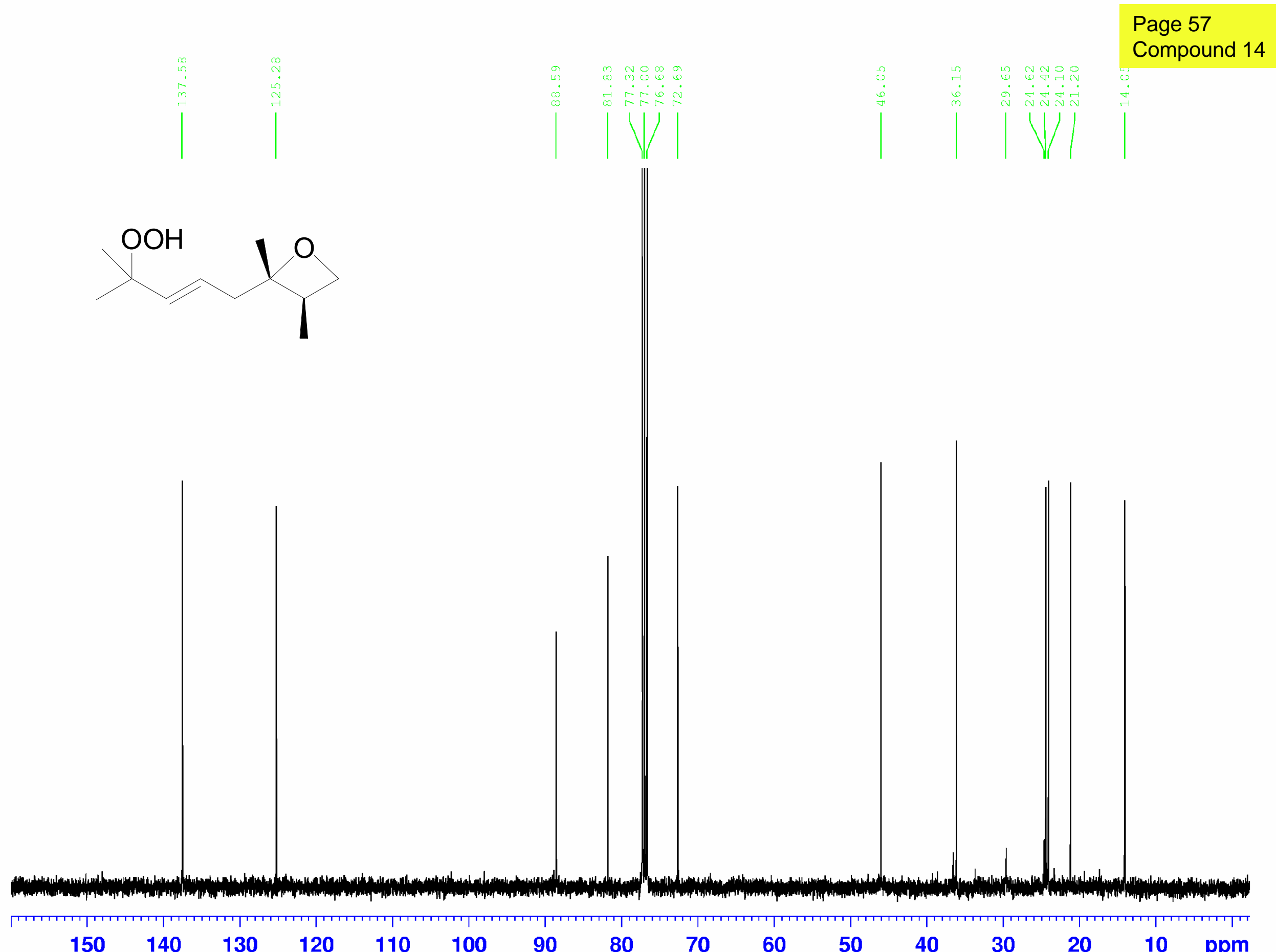


Page 58

Compound 15
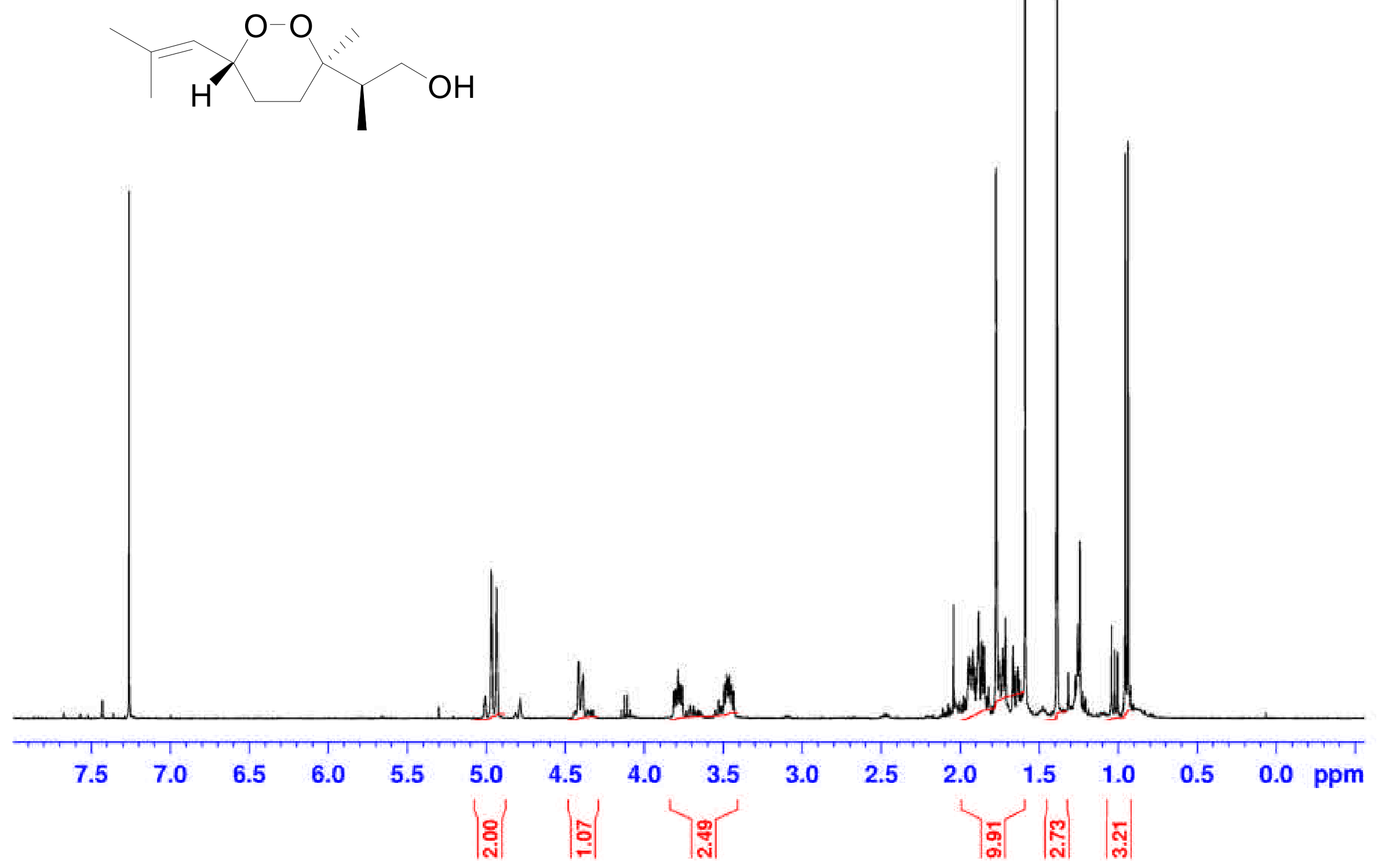
